\title{
Structure-Activity Relationships in the Design of Mitochondria-Targeted Peptide Therapeutics
}

Wayne Mitchell ${ }^{a}$, Jeffrey D. Tamucci ${ }^{a}$, Emery L. $\mathrm{Ng}^{\mathrm{a}}$, Shaoyi Liu ${ }^{\mathrm{b}}$, Hazel H. Szeto ${ }^{\mathrm{b}}$, Eric R. May ${ }^{\mathrm{a}}$, Andrei T. Alexandrescu ${ }^{a}$, and Nathan N. Alder ${ }^{a *}$

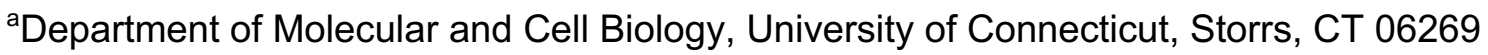
bSocial Profit Network Research Lab, Menlo Park, CA 94025

${ }^{*}$ Corresponding Author

Dr. Nathan N. Alder

91 N. Eagleville Rd

Storrs, CT 06269-3125

e-mail: nathan.alder@uconn.edu

phone: $860-486-5154$

\section{Keywords}

Mitochondria; Peptide Therapeutics; Peptide-Membrane Interactions; Quantitative StructureActivity Relationship; SS peptides; Cardiolipin; Peptide Conformation; Membrane Potential; Cation-m Interactions; NMR Structure; Molecular Dynamics, Cell Stress 


\begin{abstract}
Mitochondria play a central role in metabolic homeostasis; hence, dysfunction of this organelle underpins the etiology of many heritable and aging-related diseases. Mitochondria-targeted tetrapeptides with alternating cationic and aromatic residues, such as SS-31 (Elamipretide), show promise as therapeutic compounds. In this study, we conducted a quantitative structure-activity analysis of three alternative tetrapeptide analogs that differed with respect to aromatic side chain composition and sequence register, benchmarked against SS-31. Using NMR and molecular dynamics approaches, we obtained the first structural models for this class of compounds, showing that all analogs except for SS-31 form compact reverse turn conformations in the membrane-bound state. All peptide analogs bound cardiolipin-containing membranes, yet they had significant differences in equilibrium binding behavior and membrane interactions. Notably, the analogs had markedly different effects on membrane surface charge, supporting a mechanism in which modulation of membrane electrostatics is a key feature of their mechanism of action. All peptide analogs preserved survival and energy metabolism more effectively than SS-31 in cell stress models. Within our peptide set, the analog containing tryptophan side chains, SPN10, had the strongest impact on most membrane properties and showed greatest efficacy in cell culture studies. Taken together, these results show that side chain composition and register strongly influence the activity of these mitochondria-targeted peptides. Furthermore, this work helps provide a framework for the rational design of next-generation therapeutics with enhanced potency.
\end{abstract}




\section{Introduction}

As regulators of energy metabolism, mitochondria house the oxidative phosphorylation (OXPHOS) complexes that produce $>90 \%$ of cellular ATP. Mitochondria also coordinate key cellular processes including lipid biosynthesis, ion homeostasis, and cell death. Consequently, mitochondrial dysfunction, particularly in tissues with high energy demand, is central to the etiology of many complex pathologies including cancer, cardiopathy, neurodegeneration, agingrelated ailments, and heritable (primary) mitochondrial disease. Despite this, there are currently no FDA-approved therapeutics for the treatment of mitochondrial diseases.

Mitochondria-targeted cationic-aromatic tetrapeptides are among the most promising pharmacological interventions under development for the treatment of mitochondrial dysfunction. Also termed Szeto-Schiller (SS) peptides, these first-in-class compounds are synthetic Cterminally amidated tetrapeptides with a motif of alternating cationic and aromatic residues that is thought to be important for their ability to traverse membranes in a variety of cell types and concentrate in mitochondria (1-3). Many in vitro, preclinical, and clinical studies, predominantly with the lead compound SS-31 (Elamipretide), support the therapeutic efficacy of these peptides. Studies with isolated mitochondria and cell cultures show that SS-31 improves electron transfer efficiency and increases ATP production while reducing electron leak and reactive oxygen species (ROS) production (3-7). Furthermore, animal studies have demonstrated the ability of SS-31 to maintain cellular bioenergetics under stress conditions such as ischemia, hypoxia, and agingrelated dysfunction (8-11). Finally, the clinical efficacy of SS-31 has been demonstrated for primary mitochondrial disorders $(12,13)$ and for age-related chronic diseases associated with mitochondrial dysfunction (14).

Progress toward elucidating the molecular mechanism of action (MoA) of these peptides has come on several fronts. Early studies suggested that SS peptides target the lipid bilayers of mitochondrial membranes through interactions with cardiolipin $(C L)(4,5,15)$, the anionic phospholipid that is enriched in the inner mitochondrial membrane (IMM) and required for proper membrane morphology as well as function of membrane-bound complexes (16). This bilayermediated mechanism is supported by work with model systems in which peptide inhibited peroxidase activity of cytochrome $c$ (4) and improved cristae ultrastructure (17). Recent work from our group quantitatively evaluated SS-31 interactions with CL-containing membranes, showing that the peptide affected lamellar bilayer properties (e.g. lipid lateral diffusion and packing interactions), with the most notable effect being on membrane electrostatics based on downregulation of the surface potential $\left(\psi_{s}\right)$ that originates from the negatively-charged membrane interface (18). Other recent work has focused on the interactions of SS-31 with mitochondrial 
proteins. Based on a crosslinking/mass-spectrometry approach with a biotinylated SS-31 variant, the SS-31 interactome was shown to include a subset of membrane complexes primarily involved in ATP-generating processes (19). Moreover, in aged cardiomyocytes, SS-31 was shown to reduce proton leak mediated by the adenosine nucleotide transporter (ANT1) and stabilize the ATP synthasome (11). Notably, the vast majority of these SS-31-interactive proteins are known to bind $\mathrm{CL}$, supporting a role of mitochondrial lipid composition in the molecular interactions of these compounds. Yet despite these insights, the lack of information relating the structure and function of these mitochondria-targeted tetrapeptides presents a barrier to a full understanding of their MoA.

An effective strategy to address this mechanistic knowledge gap is to test the effects of expanding the sequence space of mitochondria-targeted peptides using structure-activity analyses. In this study, we compared three sequence-variant peptide analogs that differed with respect to aromatic side chain content and cationic/aromatic register, using SS-31 as a benchmark. Our results provide a direct comparison of these tetrapeptide variants with respect to their membrane-bound conformations, effects on membrane properties, and relative efficacies in preserving cellular viability under stress. This work reveals that side chain composition has a profound effect on the structure-activity relationships of these mitochondria-targeted peptides. Most notably, the analog containing tryptophan side chains had the greatest potency in cell stress models, which we can correlate with its molecular-level interactions and effects on reductionist membrane systems. This work sets the foundation for the rational design of next-generation tetrapeptide variants with enhanced efficacy as mitochondrial therapeutics.

\section{Results}

Tetrapeptide analog set: design and rationale

In this study, we compared a test set of four tetrapeptides with different sequences (Fig. 1A). An alphabet of two basic residues (Arg, Lys) and three aromatic residues (Phe, Tyr, Trp) gives $3^{2} \times 2^{2} \times 2=72$ possible sequence permutations with an alternating aromatic $(\varphi) /$ basic $(B)$ sequence periodicity (B- $\varphi-B-\varphi$ or $\varphi-B-\varphi-B)$. However, the number of sequences becomes much larger if $D$-amino acids (which can extend the medicinal lifetimes of peptides) and/or unnatural amino acids (which increase functional versatility) are included. A large library of peptides precludes detailed structural and functional studies, so we focused on a limited test set of peptides to investigate two fundamental properties: (i) the side chain register (B- $\varphi-B-\varphi$ vs. $\varphi-B-\varphi-B)$ and (ii) the types of aromatic side chains. The cationic/aromatic register has potential structural ramifications, for example, in determining the polar interactions between peptide basic groups 
and CL. Aromatic amino acid type can modulate hydrophobicity, aromaticity, polarity, and hydrogen bonding capacities, which in turn can affect both peptide structure and peptidemembrane interactions (20).

Our test set (Fig. 1A) included two analogs with $B-\varphi-B-\varphi$ register, SS-31 (our benchmark) and SPN4. These two analogs differ only with respect to the second-position aromatic residue. SS-31 contains the unnatural amino acid 2,6-dimethyltyrosine (Dmt), known to be important for free radical scavenging by this peptide $(1,3,21)$. By contrast, SPN4 replaces this Dmt with Tyr. Proteinogenic Tyr retains the phenolic $\mathrm{OH}$ group that can scavenge radicals and mediate $\mathrm{H}$-bond interactions but allows us to evaluate the effect of the two tyrosine methyl groups on peptide structure and function. Our test set also included two analogs with $\varphi-B-\varphi-B$ register, SS-20 and SPN10. With its Phe/Phe aromatic composition, SS-20 does not possess the free radical scavenging properties of SS-31; however, it has also demonstrated efficacy with many mitochondrial disease models (22-24), confirming that scavenging activity is not an essential feature of the MoA of this class of compounds. Finally, SPN10 is unique among our test set in that it contains only L-enantiomer side chains and it has two Trp residues, which contain the bulky bicyclic indole group with a pyrrole-like $\mathrm{NH}$ that can mediate $\mathrm{H}$-bond interactions.

\section{The free peptides are extended but have residual structure due to aromatic interactions}

As a first step toward comparing the four peptides, we determined their NMR structures in solution. Small water-soluble and membrane-active peptides typically adopt their bioactive conformations only upon binding membranes $(25,26)$. However, even very short peptides can have preferred conformations in aqueous solution (27), particularly if they are enriched in aromatic residues. Structural analysis of these peptides in solution can shed light on their properties in the extracellular milieu, the cytosol, and aqueous mitochondrial subcompartments.

NMR spectra of the peptides were assigned using 2D TOCSY and NOESY spectra for ${ }^{1} \mathrm{H}$ signals, and ${ }^{1} \mathrm{H}-{ }^{13} \mathrm{C} \mathrm{HSQC}$ and ${ }^{1} \mathrm{H}-{ }^{15} \mathrm{~N}$ HSQC experiments with samples at natural isotope abundance for ${ }^{13} \mathrm{C}$ and ${ }^{15} \mathrm{~N}$ nuclei, respectively (Table S1). The free peptides in solution show few, if any, NOEs (Fig. S1A), which is consistent with their molecular masses of $\sim 600 \mathrm{Da}$ as this is near the zero-crossing point for the NOE (28). To characterize their structures in solution, we therefore collected rotating frame data (ROESY) (28) as the signs of crosspeaks in this experiment are invariant to molecular size (Fig. S1B). We obtained roughly 30-50 distance constraints per peptide, or 10 NOEs per residue, for NMR structure calculations (Table S2). The resulting free peptide structures are relatively disordered extended conformations (Fig. 1B). However, we did observe some residual structure influenced by the side chain register. 
Specifically, tetrapeptides with a B- $\varphi-B-\varphi$ motif (SS-31 and SPN4) had lower root-mean-squared deviation (RMSD) values (better structural precision) and three non-sequential NOEs, whereas those with a $\varphi-B-\varphi-B$ motif (SS-20 and SPN10) lacked non-sequential NOEs (Table S2). Importantly, the non-sequential NOEs in SS-31 and SPN4 occurred between the two aromatic residues, consistent with previous observations that residual structure is more common in short peptides containing aromatic side chains $(29,30)$. Additional interactions that appear to stabilize the tetrapeptide structures in solution are cation- $\pi$ interactions between neighboring basic and aromatic amino acids. These are supported by significant upfield ring current shifts for some of the basic residue side chain nuclei (Table S1), for all peptides except SS-31.

As a second approach to assessing peptide solution structures, we performed all-atom MD simulations (200 ns each) of the peptides in an aqueous environment. To initiate each simulation, the solution structure of each peptide closest to the mean of the NMR ensemble was used. To directly compare the ensemble of structures from our NMR- and MD-based approaches, we calculated the RMSD to the ensemble average and the radius of gyration $\left(R_{\mathrm{g}}\right)$ values. For all peptides, the MD-derived ensemble had greater structural variability (higher RMSD) and were less compact (higher $R_{\mathrm{g}}$ ) than their cognate NMR-derived structures (Fig. 1C, compare black squares and circles). However, consistent with our NMR results, the RMSD values calculated by MD simulations were lower for SS-31 and SPN4 than for SS-20 and SPN10 (Fig. S2). Notably, all of these RMSDs were lower than the limiting RMSDs for tetrapeptides with random structures, which we calculate to be on the order of 3 to $5 \AA$ (see Methods). Taken together, the results of our NMR and MD analyses suggest that the free peptides are largely disordered but retain some residual structure due to cation- $\pi$ and aromatic ring stacking interactions. We next proceeded to empirically evaluate the interaction of our tetrapeptides with biomimetic membranes.

Tetrapeptide analogs have distinct equilibrium binding behavior to cardiolipin-containing membranes

To assess the membrane binding properties of the peptide analogs, we performed isothermal titration calorimetry (ITC) of peptides titrated with large unilamellar vesicles (LUVs) containing a 20:80 molar ratio of 16:0/18:1 phosphatidylcholine (POPC) and 18:1 CL (tetraoleoylCL, TOCL) (Fig. 2). This approach provides a full thermodynamic characterization of the peptidemembrane interaction. Fits to binding isotherms (Fig. 2A) provided equilibrium binding parameters (Fig. 2B) that revealed key similarities and differences among the membraneinteractive properties of our test set. First, all tetrapeptides bound CL-containing membranes with roughly similar binding affinity $\left(K_{\mathrm{D}} 27.5 \mu \mathrm{M}\right.$ to $39.5 \mu \mathrm{M} ; \Delta G-26.2 \mathrm{~kJ} / \mathrm{mol}$ to $\left.-25.9 \mathrm{~kJ} / \mathrm{mol}\right)$ that did 
not differ significantly among the analogs tested. However, the lipid-to-peptide binding stoichiometry, $n$, did differ among peptides. Compared with the benchmark SS-31 ( $n=5.4$; i.e., an average of 5.4 lipids per bound peptide), SPN4 had a similar value ( $n=5.7)$, SS-20 had a significantly higher value $(n=7.4)$, and SPN10 had a significantly lower value $(n=3.3)$. These results indicate that SPN10 and SS-20 bind membranes, respectively, at higher and lower surface densities than SS-31.

Membrane interaction of all peptides was enthalpically favorable $(\Delta H<0)$ but dominated by favorable entropy (T $\Delta S>0$ ), as observed previously for SS-31 (18). In comparison with the binding enthalpy of SS-31 $(\Delta H=-5.1 \mathrm{~kJ} / \mathrm{mol})$, SPN4 had a similar value $(\Delta H=-4.5 \mathrm{~kJ} / \mathrm{mol})$, whereas the magnitude of binding enthalpy was significantly lower for SS-20 $(\Delta H=-3.2 \mathrm{~kJ} / \mathrm{mol})$ and higher for SPN10 $(\Delta H=-7.1 \mathrm{~kJ} / \mathrm{mol})$. As $\Delta H$ is a function of polar contacts made during binding (31), this trend in $\Delta H$ is consistent with the number of aromatic side chains containing polar groups (SPN10, two indole NH groups; SPN4/SS-31, one phenol OH group; SS-20, none). Binding entropy, which in this system is largely a function of aromatic side chain partitioning into the acyl chain region (31), did not differ significantly among peptides (T $\Delta S$ ranged from 19.0 $\mathrm{kJ} / \mathrm{mol}$ to $22.1 \mathrm{~kJ} / \mathrm{mol}$ ). However, the relative enthalpic and entropic contributions to binding, quantified by the ratio $\mathrm{T} \Delta \mathrm{S} /|\Delta \mathrm{H}|$, indicate that in comparison with SS-31, membrane binding of SS-20 is more entropy-driven and that of SPN10 is more enthalpy-driven. Having established these differences in membrane binding behavior among our peptide analogs, we then investigated their structural differences in the membrane-bound state.

\section{The bicelle-bound peptides adopt distinct reverse turn structures, except for SS-31}

To determine the structural features of cationic-aromatic tetrapeptides in a membrane-like environment, we used bicelles as membrane mimetics. We hypothesized that moving from a high to a low dielectric environment would promote a more uniform structure and that the measured differences in the membrane-binding thermodynamics of these peptides could have a structural basis. As previously reported (4), in the presence of cardiolipin-containing bicelles, the NMR signals of SS-31 broadened at low peptide:lipid ratios, and then sharpened again at a molar excess of peptide to cardiolipin. This indicates that the free and bicelle-bound states of the peptides are in fast exchange on the NMR time-scale and should be amenable to transferred NOE (trNOE) studies (32). We confirmed this by observing that a large number of negative NOEs, consistent with a high MW peptide-bicelle complex, are transferred to the free peptide (Fig. S1C, Fig. S3). These trNOEs allowed us to calculate structures for all four peptides in their bicellebound states (Table S3), as shown in Fig. 3. The NMR structures are precise because they are 
each defined by 95-110 trNOEs per tetrapeptide, or about 25 structural restraints per residue (Table S3). This is reflected in heavy atom RMSDs values of 0.5-0.9 $\AA$ for the bound peptides, which is less than half of those of the free peptides (Fig. 1C, Table S4). NMR structures of all the peptide analogs had lower RMSD and $R_{\mathrm{g}}$ values in the membrane-bound relative to the free state. In other words, they became more structurally constrained and compact upon binding (Fig. 1C, compare black and red squares). The exception was SS-31, whose RMSD and $R_{\mathrm{g}}$ values did not statistically change upon binding.

Interestingly, we found that in the membrane-bound state, all peptide analogs except for SS-31 formed $\mathrm{H}$-bonded reverse turn structures with basic side chains pointing away from the plane of the backbone ring (Fig. 3A). This gives the peptides a markedly asymmetric charge distribution (Fig. S4), with the cationic face of the peptides likely poised for binding to the negatively charged lipid phosphates of CL-containing membranes. To form the reverse turn structures, the $\varphi-\mathrm{B}-\varphi$-B peptides have $\mathrm{CO}(1)$ to $\mathrm{NH}(4) \mathrm{H}$-bonds. However, for the $\mathrm{B}-\varphi$ - $\mathrm{B}-\varphi$ peptide SPN4, the $\mathrm{H}$-bond is formed with the capping $\mathrm{NH}_{2}$ group that essentially acts as the amide proton donor of a non-existent fifth residue in a $\mathrm{CO}(2)$ to $\mathrm{NH} 2(5)$ pattern (Fig. 3B). In contrast, the other B- $\varphi-B-\varphi$ peptide SS-31 adopts an extended conformation due to steric restraints induced by the methyl groups on Dmt2 that preclude the turn conformation from forming. For the peptides that form a reverse turn, intra-peptide cation- $\mathrm{T}$ interactions are observed and the backbone $\mathrm{H}$-bond $\mathrm{NH}$ donor in the turn structure is always an aromatic residue. For the $\varphi-B-\varphi-B$ peptides SS-20 and SPN10, cation- $\pi$ interactions form between Arg2, Phe3 and Trp3, Lys4, respectively. Although these cation- $\pi$ interactions may arise simply from sequence proximity, they could play a critical role in reducing the overall polar character of these peptides, allowing them to traverse low-dielectric cellular structures. As for the basic residues, Arg is always the more poorly defined side chain in the structures and Lys is generally precisely defined, suggesting that the latter might be experiencing restricted motion due to partial insertion in the membrane (Fig. 3A).

We also evaluated the membrane-bound structures of the four tetrapeptides using MD simulations, where multiple peptides were allowed to associate with a bilayer consisting of an 80:20 molar ratio of POPC:TOCL (Fig. 4A). All peptides rapidly adsorbed to the membrane surface within 500-750 ns and evolved towards a stable, bound configuration over the course of the $2 \mu$ s simulations (Fig. S5-S9). As with the solution structures, membrane-bound structures from MD had higher RMSD and $R_{\mathrm{g}}$ values than those from NMR (Fig. 1C, Table S4).

To further compare our membrane-bound MD and NMR structures, we calculated the average fraction of time each peptide in the simulation was within $3 \AA$ heavy atom RMSD to the NMR top structure. Overall, the MD ensembles had a low frequency of sampling states with high 
similarity to the NMR-derived structures (Fig. 4B, Table S5). This low degree of structural overlap motivated the extension of each simulation for an additional $1 \mu \mathrm{s}$, during which NOE distance restraints between residues $i$ to $i+2$ and $i$ to $i+3$ were imposed for each peptide (33-35). Imposing the NMR restraints yielded considerable improvements in structural similarity to the NMR structure for all peptides (Fig. 4B, Table S5). NOE violations were computed over the MD simulations using time and ensemble averaging and violations occurred less than $20 \%$ of the time for the majority $(\sim 71 \%)$ of the applied restraints (Fig. S10). Thus, all subsequent MD analyses were performed using NOE restrained MD data, unless otherwise indicated.

\section{Peptide analogs have different membrane insertion profiles and lipid interactions}

We next analyzed our MD simulations for the membrane insertion depth of each peptide side chain. Side chain insertion depth $\left(Z^{\text {pos }}\right)$ for each peptide analog was measured by averaging the distance in the Z-direction (bilayer normal) from each side chain's $\mathrm{C} \beta$ atom to the bilayer center of mass (COM) (Fig. 4C, Fig. S5-S9). Generally, the residues of SS-31 tended to bury deepest, followed sequentially by SPN10, SS-20, and SPN4.

In the trNOE experiments, we also observed NOEs between the peptides and the bicelle lipids, for which we used lipid proton assignments from the literature (Fig. S11-S12) (36). Most of the peptide-lipid NOEs were from aromatic residues to lipid protons close to the headgroup region. This suggests peptides are superficially buried in the interfacial region of lipid bilayers, in agreement with the MD results. Interestingly, the peptide-lipid NOEs for SPN10 were generally weaker than those of the other peptides (Fig. S12). Although we saw few, if any, trNOEs from lipid to the basic groups, this could be explained by the fact that the TOCL ${ }^{1} \mathrm{H}$ signals were largely overlapped and dominated by the $\sim 40$-fold molar excess of DHPC and POPC (Fig. S11). Additionally, given the $1 / r$ distance dependence of charge-charge interactions, long-range electrostatic effects could be missed by the $\sim 5 \AA$ detection threshold of the NOE.

\section{SPN10 minimizes membrane surface area and CL self-interactions}

We next used MD simulations to obtain insights into the effects of peptide binding on bilayer properties. We first considered molecular exposure at the membrane-solvent interface by calculating the solvent accessible surface area (SASA) of different groups (Fig. 4D, Fig. S13). We measured the total membrane and peptide SASA of a given system in addition to its component headgroup, acyl chain, and peptide SASA values in the presence and absence of peptides. In the absence of peptides, total membrane SASA can be parsed into headgroups, which constitute the majority of solvent-exposed area, and acyl chains, whose exposure can be 
interpreted as interfacial lipid packing defects $(18,37)$. As expected, the presence of all peptides at the bilayer interface reduced both lipid headgroup and acyl chain SASA, due to peptides "covering" the bilayer surface. Among the four analogs, SS-20 and SPN4 were more highly solvent exposed, consistent with their more superficial binding near the solvent interface (Fig. 4C). By comparison, SS-31 and SPN10 caused the greatest decrease in acyl chain SASA, consistent with their deeper burial into the nonpolar core (Fig. 4C), filling the "voids" of solventexposed hydrocarbon chains. The most notable distinction between the more deeply buried SS31 and SPN10 was that SPN10 also caused a significantly lower headgroup SASA. Hence, SPN10-containing bilayers had the lowest total SASA among all peptide analogs, and SPN10 was the only peptide to not significantly change the total SASA compared to the bilayer-only system. The observation that total SASA is unchanged when SPN10 binds the bilayer indicates that the total amount of surface that is "created" by this bound peptide is approximately equal to the total amount of bilayer surface area that is "buried" by it.

Second, we considered peptide-induced elastic deformations of the bilayer, namely crosssectional area per lipid and bilayer thickness (Fig S14). Our measurements of these parameters before peptide binding (i.e., peptides restrained in solution) were consistent with previous MD work from our group $(18,37,38)$ and others (39). Upon peptide binding, we observed an inverse trend between bilayer thickness (Fig. S14 A,B) and mean lipid area (Fig. S14 C,D). SS-31 and SPN10 expanded mean lipid area (decreased bilayer thickness) to a greater extent than did SPN4 and SS-20, which is likely related to the deeper burial of SS-31 and SPN10 aromatic side chains into the membrane (Fig. 4C). The combined observations that SPN10 both expanded membrane area (Fig. S14) and maintained the lowest total SASA (Fig. 4D) among our peptide set suggests that even though this analog causes elastic bilayer expansion, it maintains a low "ruggedness" of exposed membrane surface (40).

Finally, we constructed radial distribution profiles to determine peptide-lipid and lipid-lipid interactions in the lateral (x-y) plane of the membrane (Fig. S15). As a proxy for peptide-lipid association (Fig. S15, upper pane/s), we chose the $\mathrm{C} \zeta$ atom of the Arg at the first (SS-31/SPN4) or second (SS-20/SPN10) position. We observed three radial shells of POPC and TOCL phosphates around each Arg. SS-31 and SPN4 had a greater density of CL phosphates in the closest shells, whereas CL phosphates of distal radial shells were more populated for SS-20 and SPN10. This may be related to the proximity of the Arg to the cationic $\mathrm{NH}_{3}$ terminus in the B- $\varphi-\mathrm{B}-$ $\varphi$ peptides causing greater local density of anionic CL. The distribution profiles of Arg-PC were, by comparison, much more similar among peptides. Our analysis of lipid-lipid radial distributions (Fig. S15, lower panels) revealed four radial densities of lipid phosphates around corresponding 
phosphates of CL or PC. CL phosphates in the same Z-plane do not often approach closer than $\sim 5 \AA$ (18), likely due to charge-charge repulsion. Notably, SS-31 caused an increased density of $\mathrm{CL}$ around itself at distances $<6 \AA$, suggesting that SS-31 may draw CL phosphates out of their respective Z-plane more than other analogs, perhaps consistent with this peptide's membranethinning effects (Fig. S15). By comparison, SPN10 disfavored close contact of CL, which may be related to its large aromatic Trp side chains inhibiting close approach of sterically bulky CL.

\section{SPN10 has a markedly greater effect on membrane electrostatics}

Our previous work showed that SS-31 modulates membrane surface electrostatics as a key part of its molecular MoA (18). We therefore sought to evaluate the effects of our four peptide analogs on membrane electrostatic potentials (Fig. 5). We first analyzed surface potential $\left(\Psi_{s}\right)$, which originates from fixed charges at the interface and is strongly negative for CL-rich mitochondrial membranes $(41,42)$. To this end, we used the fluorescent reporter probe ANS, which reversibly binds anionic membranes, with corresponding increase in quantum yield, in a manner that is promoted by $\Psi_{\mathrm{s}}$ attenuation $(42,43)$. As we have shown, ANS profiles are consistent with zeta potential readouts of membrane surface charge (18). We first measured the effect of peptide analogs on the surface charge of mitochondrial membranes by titrating mitoplasts (mitochondria with disrupted outer membrane) with peptide (Fig. 5A). All peptides caused a saturable decrease in membrane surface charge, with SPN10 causing markedly higher attenuation (Fig. 5A, left); by comparison, within the resolution of this assay, there was no discernible difference in saturation binding among peptides (Fig. 5A, right). These results support that the highest $\Psi_{\mathrm{s}}$ down-regulation is caused by SPN10 in organello, but do not rule out that this could be caused by peptide interaction with mitochondrial proteins. We therefore repeated this analysis in a more reductionist system with CL-containing LUVs (Fig. 5B). Again, SPN10 showed the greatest effect on $\Psi_{s}$ in this lipid-only system (Fig. 5B, left) despite all analogs having similar saturation curves (Fig. 5B, right). Taken together, these results show that SPN10 is a markedly more potent attenuator of membrane surface charge, originating from down-tuning of lipid bilayer surface charge.

We next analyzed membrane dipole potential $\left(\Psi_{\mathrm{d}}\right)$, which originates from the arrangement of interfacial lipid and water dipoles, and contributes significantly (several hundred $\mathrm{mV}$ ) to membrane electrostatic profiles (44) (Fig. 5C). Importantly, $\Psi_{\mathrm{d}}$ influences the translocation of hydrophobic ions across bilayers and may affect binding interactions with peptides (45). To evaluate the effects of our peptide analogs on $\Psi_{d}$, we used ratiometric fluorescence excitation measurements of the membrane-bound probe di-8-ANEPPS, which has been shown to report 
dynamic changes in $\Psi_{\mathrm{d}}$, of model membranes $(46,47)$. Titration of LUVs with peptides resulted in a saturable reduction in $\Psi_{\mathrm{d}}$ (Fig 5C, left) with fractional binding (Fig 5C, right) consistent with our ITC-based binding curves (Fig. 2). These results indicate that all peptides cause saturable disordering of lipid and/or water dipoles upon binding. Furthermore, SS-20 had a markedly weaker effect than the others, possibly due to its comparatively lower aromatic bulk and/or lack of polar groups on aromatic side chains.

Lastly, we tested the effect of our peptides on the transmembrane potential $\left(\Delta \Psi_{\mathrm{m}}\right)$, which is based on ion asymmetry across the IMM established by OXPHOS proton pumping (48). Both SS-31 and SS-20 have been shown to have no effect on $\Delta \Psi_{m}$ in healthy mitochondria $(3,18)$, and it is crucial to verify that other mitochondria-targeted peptides have no IMM-uncoupling properties. To test this, we used the potentiometric probe TMRM, whose fluorescence quenches upon accumulation in the matrix of energized mitochondria (49). No peptides had any measurable effect on the TMRM-detected magnitude of $\Delta \Psi_{m}$ (Fig. 5D), indicating that they neither hyperpolarize nor depolarize the IMM.

Taken together, these mitochondria-targeted tetrapeptides modulate membrane electrostatic potentials differently, in ways that depend on their side chain compositions. Most notable was the effect of SPN10 on $\Psi_{\mathrm{s}}$, which we propose to be a key underpinning of the activity of these peptides (18). Having addressed key aspects of their molecular structure and behavior, we proceeded to test how these features of our tested peptides relate to their efficacy in ameliorating stress using cell culture models.

\section{Cellular activity of CL-binding peptides}

Therapeutic efficacy requires cationic-aromatic peptides to be cell-permeable. Although this has been extensively demonstrated for SS-31 $(B-\varphi-B-\varphi)(2,3)$, it was unclear if analogs with $\varphi-B-\varphi-B$ sequence would behave similarly. We therefore compared the cell uptake and mitochondrial localization of N-biotinylated SS-31 and N-biotinylated SPN10, in human kidney epithelial cells (HK-2) and retinal pigment epithelial cells (ARPE-19). The two biotinylated peptides readily penetrated both cell lines within an hour and showed a mitochondrial localization pattern (Fig. 6A).

Extensive studies have shown that SS-31 promotes cell survival under a variety of stress challenges, including ischemic, hypoxic, metabolic, and oxidative stress conditions (10). Serum starvation is frequently used as a stress model in cell cultures, since it causes decreases in cellular ATP, cell cycle arrest, and apoptosis (50-52). The effects of the four test peptides on cell viability and ATP levels were examined in HK-2 cells seven days after serum removal. Treatment 
with the four peptide analogs at concentrations of $10 \mathrm{nM}$ significantly increased cell viability in HK-2 cells, with SPN10 being significantly better than SS-31 ( $<0.001)$ (Fig. 6B). Cellular ATP content was also significantly elevated by the four peptides, and SPN10 was again better than SS-31 ( $<$ < 0.001) (Fig. 6C). In addition, SPN10 significantly raised ATP levels in ARPE-19 cells with serum starvation (Fig. 6C).

\section{Discussion}

The objective of this study was to evaluate the effects of modifying two key features of mitochondria-targeted peptides, side chain composition and sequence register, to better understand what chemical properties are important for their therapeutic efficacy. SS-31 and SS20, which have both been validated in pre-clinical and clinical tests, feature different aromatic side chains and ordering of cationic and aromatic groups. The efficacy of these compositionally distinct peptides motivated us to test the structural and functional consequences of further modifications in the cationic-aromatic motif of these peptides. All four analogs were found to bind CL-containing bilayers, modulate membrane electrostatics, and show efficacy in cell stress models. Collectively, these observations support the concept that this general motif is sufficient for the molecular action of these mitochondria-targeted compounds. Yet there were also marked differences in their structures and molecular behaviors. These differences provide critical insights into the MoA of this class of compounds that can be leveraged to develop more effective mitochondrial therapeutics.

A central aim of this study was the structural characterization of these peptides in solution and in the membrane-bound state. To this end, we used complementary approaches of NMR spectroscopy and MD simulations, providing the first models of the structures of these compounds. As expected, all peptides are largely disordered in solution (Fig. 1B, Fig. S2) and assumed a more compact and well-defined structure when membrane-bound (Fig. 3). This trend is reflected by the general decrease in the calculated RMSD and $\mathrm{R}_{g}$ seen for the bound structures (Fig. 1C). Intra-peptide aromatic ring stacking and cation- $\pi$ interactions are stabilizing features of both the solution and membrane-bound states (Fig. 1B, Fig. 3). This point is significant because cation- $\pi$ complexes are known to lower the energetic cost of partitioning basic side chains into the nonpolar membrane core $(53,54)$, which likely contributes to the ability of these tetrapeptide analogs to traverse cell membranes, including those of the blood-brain barrier $(2,55)$, and to reside stably at the membrane interface.

The most notable structural feature of these tetrapeptides is the membrane-bound reverse-turn conformation observed for all analogs other than SS-31. These conformers can all 
be formally classified as four-residue beta turns stabilized by an $i$ to $i+3$ main chain $\mathrm{H}$-bond with an $\mathrm{C} \alpha(1)$ to $\mathrm{C} \alpha(4)$ distance of $\sim 7 \AA$ or less $(56,57)$. The dihedral angles of the $i+1$ and $i+2$ residues of these structures deviated from the canonical $\phi / \psi$ values for the most common beta turns; however, with increasing availability of high-resolution protein structures, it is becoming clear that the central residues of beta turns can occupy a wider diversity of Ramachandran space than previously appreciated (58). The $\varphi$-B- $\varphi$-B peptides (SS-20 and SPN10) are stabilized by a CO(1) to $\mathrm{NH}(4) \mathrm{H}$-bond, whereas the $\mathrm{B}-\varphi-\mathrm{B}-\varphi$ peptide (SPN4) is stabilized by an $\mathrm{H}$-bond between $\mathrm{CO}(2)$ and the C-terminal amide group (in lieu of a 'fifth' residue) (Fig. 3). This latter feature underscores the importance of C-terminal amidation in these compounds: not only does the amide remove the C-terminal carboxyl function to maintain the net +3 charge of these compounds, but as shown in this study, it also provides an $\mathrm{H}$-bond donor to stabilize the turn structure of peptides with $\mathrm{B}-\varphi$-B$\varphi$ register. Given that the $\mathrm{H}$-bonds of these reverse turn structures reside in the low-dielectric microenvironment of the membrane interface, they are likely to be more stabilizing than when in bulk aqueous solution (59). By partially satisfying the $\mathrm{H}$-bonding capacity of main chain atoms, this $i$ to $i+3$ polar interaction partially offsets the energetic penalty of dehydration of polar backbone functional groups at the membrane, which may in turn allow the peptides to reside near the polar-apolar boundary of the membrane. From these findings, one possibility to explore is the synthesis of cyclized forms of these peptides, given that forcing the peptides to adopt the bioactive pose may lessen the entropic penalty of membrane binding.

Our results provide several insights into the nature of the interaction between the tetrapeptides and lipid bilayers. The first insight pertains to peptide binding density (Fig. S16). Based on the lipid:peptide stoichiometries $(n)$ from our ITC analyses (Fig. 2), coupled with the known cross-sectional areas of POPC $\left(70 \AA^{2},(60)\right)$ and TOCL $\left(129 \AA^{2},(37)\right)$, one can calculate the binding footprint of peptides in the bilayers (80:20 POPC:TOCL) used for ITC. In increasing order, the per-peptide membrane areas are: $270 \AA^{2}$ (SPN10) < $434 \AA^{2}$ (SS-31) < $466 \AA^{2}$ (SPN4) $<605 \AA^{2}$ (SS-20). Hence, SPN10 has greater binding density, and SS-20 has lower binding density, compared with SS-31/SPN4. Given that the mitochondrial IMM is protein-rich with little free exposed bilayer (61), the greater per-peptide membrane coverage of SPN10 may relate to its enhanced efficacy by increased occupancy of the limited lipid area of mitochondria (Fig. S16). This leads to a second related insight from this work regarding the effects of these peptides on membrane surface area. Our previous work showed that SS-31 caused a decrease in acyl chain SASA, likely related to a decrease of interfacial hydration and increased lipid packing density (18). In the present study, we found that SPN10 stood apart from the other peptides in that it minimized solvent exposure of both lipid aliphatic chains and headgroups, thereby resulting in total 
membrane SASA similar to membranes in the absence of peptide (Fig. 4D). This ability of SPN10 to fill packing defects is likely related to a combination of factors, including its large aromatic side chain volume, its deeper binding in the membrane interface (Fig. 4C), and its high surface coverage (Fig. 2). Within the IMM, the inverted conical geometry of CL creates lateral packing defects of lamellar bilayers (37), which could be related to transient pore-like defects that allow small molecule permeation (62) and/or accessibility of acyl groups to pro-oxidants that cause lipid peroxidation (63). Reducing lipid packing voids could be part of the MoA of these tetrapeptides, contributing to the observed decrease in proton leak across the IMM (11) and lipid oxidative damage $(1,64-66)$ that occurs with SS-31 treatment. A final related point pertains to specific peptide-lipid interactions. Our trNOE (Fig. S12) and MD (Fig. 4C) results both indicate that bound peptides reside in the membrane interface, likely within the boundaries of the lipid phosphate and ester groups. Yet the peptide analogs may mediate different lipid interactions. Compared with other peptides, the NOEs of SPN10 to lipid protons were notably fewer and weaker (Fig. S12). This may be related to our MD radial distribution profiles showing that the Arg of SPN10 has a preferential lateral accumulation of POPC over TOCL (Fig. S15). Understanding exactly how specific side chain-lipid chemical interactions relate to the efficacy of these tetrapeptide analogs will require further investigation.

Our calorimetric binding analysis showed unexpected differences in the thermodynamics of the interactions of these peptides with CL-containing membranes (Fig. 2). All analogs had roughly equal $K_{D}(\Delta G)$ values, with binding dominated by favorable changes in entropy (mean $\mathrm{T} \Delta \mathrm{S} /|\Delta \mathrm{H}|$ ranged from 2.7 to 6.9). However, compared with SS-31/SPN4, the binding of SPN10 and SS-20 had larger and smaller enthalpic binding components, respectively. These features may be interpreted in terms of the origins of $\Delta S$ and $\Delta H$ for peptide-membrane interactions. First, the entropic cost of small peptide binding that comes from restricting conformational, translational and rotational degrees of freedom (adsorption entropy) is likely to be small based on theoretical considerations (67). Instead, the large and favorable binding entropy we observe originates largely from the classical hydrophobic effect: membrane penetration of aromatic side chains is attendant with increased solvent mobility that accompanies the desolvation of the peptide and the release of ordered waters from nonpolar acyl surfaces (31). We propose that membrane binding of SS-20 is dominated by entropically favored burial of its aromatic Phe side chains, which lack polar groups, in the nonpolar membrane core. This may facilitate deeper burial of SS-20 aromatic rings in the acyl chain region, consistent with its larger binding footprint. By comparison, binding enthalpy originates largely from polar interactions between peptide and lipid headgroups. We propose that membrane binding of SPN10 is strongly favored by polar interactions involving the 
indole $\mathrm{NH}$ hydrogen bond donors of its Trp side chains. Trp is known to remain partially in the interfacial region due to its large rigid paddle-like structure (68-72), which may be consistent with its higher observed binding density. Finally, our analysis suggests that the interaction of these peptides with membranes shows enthalpy-entropy compensation, wherein the binding energy of a congeneric series of compounds remains relatively constant due to opposing changes in $\Delta \mathrm{H}$ and $\Delta S(73)$, as observed with the surface interactions of different peptides $(74,75)$. Hence, from a molecular engineering perspective, optimizing the efficacy of these tetrapeptides might be directed less toward enhancing binding affinity per se and more toward enhancing the enthalpic contribution, particularly by modulating polar contacts among aromatic groups.

This work revealed striking differences among the peptides in terms of their effects on membrane electrostatic potentials (Fig. 5). First, the $\Psi_{\mathrm{s}}$ of negatively-charged membranes (biomimetic liposomes and mitoplasts) was attenuated by all peptides (Fig. 5A,B); however, SPN10 had the greatest effect by far. This may be related in part to the higher binding density of SPN10. However, it may also be related to SPN10 uniquely having two aromatic side chains with polar (indole $\mathrm{NH}$ ) groups that can each mediate $\mathrm{H}$-bond interactions with lipid phosphates, which can alter ionization behavior and reduce headgroup charge $(76,77)$. Second, the $\Psi_{d}$ of bilayers, related to the ordering of lipid polar groups and interfacial waters, was down-regulated by all peptides (Fig. 5C). This may be due to a general effect of bound peptide causing disorganization of interfacial water dipoles. However, as a group, those peptides with polar groups on their aromatic side chains (SPN4, SS-31, SPN10) attenuated $\Psi_{\mathrm{d}}$ much more than the peptide lacking aromatic polar groups (SS-20); hence, it is possible that polar contacts with lipid mediated by aromatic side chains may alter the orientation of lipid headgroup dipoles (e.g., the P-N vector of the phosphate-choline dipole of PC (78)). Finally, it is notable that no peptide affected the $\Delta \Psi_{\mathrm{m}}$ (Fig. 5D), supporting that they do not depolarize mitochondrial membrane potentials. Taken together, this work supports our working model (18) that the tuning of $\Psi_{\mathrm{s}}$ is a key part of the MoA of these peptides, correlated with efficacy.

Our evaluation of these peptide analogs in cell culture studies provided the most relevant ranking of their relative effectiveness (Fig. 6). All analogs targeted mitochondria (Fig. 6A) and, to varying degrees, restored viability and ATP content in serum starvation models of cell stress relative to vehicle-only control (Fig. 6B,C). In these tests, analogs SPN4, SS-20 and SPN10 consistently outperformed SS-31; based on our structural analysis, this difference in efficacy could be related to the ability of the analogs to form compact folds when membrane-bound. Most notably, SPN10 showed the greatest potency in cell stress recovery. 
In summary, as the first structure-activity analysis for this class of compounds, this study provides new insights to guide their potential optimization. Given the complexity of membrane interactions in the molecular MoA of these compounds (18), coupled with the fact that membrane protein interactions are involved in their activity (19), our limited test set of four analogs could not unequivocally address all chemical features that may enhance function. But insofar as the composition and activity of SPN10 could provide a direction for optimization, the engineering of future analogs may be guided by: (i) greater bulk of aromatic R groups (which, among proteinogenic amino acids, means emphasizing Trp); (ii) ability to form compact (reverse-turn) structures when membrane-bound; (iii) polar groups on aromatic side chains that enhance enthalpy of membrane interactions; (iv) ability to decrease SASA of lipid groups; and (v) ability to down-regulate membrane $\Psi_{\mathrm{s}}$. Together, modulation of these features will help pave the way for rational design of next-generation variants of this class of mitochondria-targeted therapeutic compounds.

\section{Materials and Methods}

Reagents

Peptides SS-31, SS-20, SPN4 and SPN10 were prepared by solid-phase synthesis as TFA salts by Phoenix Pharmaceuticals (Burlingame, CA). Powder stocks were reconstituted to a concentration of $10 \mathrm{mM}$ as aqueous solutions and stored at $-20^{\circ} \mathrm{C}$. Synthetic phospholipids were purchased as chloroform stocks form Avanti Polar Lipids (Alabaster, AL), including POPC (1palmitoleoyl-2-oleoyl-sn-glycero-3-phosphocholine), DHPC (1,2-diheptanoyl-sn-glycero-3phosphocholine), and TOCL (1',3'-bis[1,2-dioleoyl-sn-glycero-3-phospho]-sn-glycerol). All lipid stocks were stored at $-20^{\circ} \mathrm{C}$ in clear glass vials with Teflon-lined cap closures. Fluorescent probes TMRM, ANS, and di-8-ANEPPS were purchased from Thermo Fisher Scientific (Waltham, MA). All solutions were prepared with ultrapure water (Millipore Advantage A10 system; resistivity 18.2 $\mathrm{M} \Omega \cdot \mathrm{cm} @ 25^{\circ} \mathrm{C}$; total oxidizable carbon $\leq 4 \mathrm{ppb}$ ).

\section{Isothermal Titration Calorimetry}

ITC measurements were performed based on well established procedures (79) that we have previously used to measure peptide-membrane interactions (18). Solutions of peptide (titrate) and LUVs (titrant) were prepared in $20 \mathrm{mM} \mathrm{HEPES-KOH}, \mathrm{pH} 7.5$, and lipid-into-peptide titrations were performed with a low-volume nano-ITC microcalorimeter (TA Instruments, New Castle, DE). The calorimeter cell (volume $170 \mu \mathrm{l}$ ) contained 125-175 $\mu \mathrm{M}$ peptide and LUVs (20 mol\% TOCL / $80 \mathrm{~mol} \%$ POPC, $8 \mathrm{mM}$ total lipid) were injected in aliquots of $2.5 \mu \mathrm{l}$ (20 total 
injections) at time intervals of $300 \mathrm{~s}$ at $25{ }^{\circ} \mathrm{C}$. To account for heats of dilution, experiments were performed by the addition of titrant into solutions of buffer only, which were used for baseline subtraction. Data from dilution-corrected and integrated heat flow time courses were fit as Wiseman plots (modeled as independent, identical single binding sites), from which equilibrium binding and thermodynamic parameters $\left(K_{d}, n, \Delta H\right.$, and $\left.\Delta S\right)$ were determined by nonlinear regression fits (NanoAnalyze software version 3.10.0, TA Instruments).

\section{Fluorescence Spectroscopy}

Steady-state fluorescence measurements were performed with a Fluorolog 3-22 spectrofluorometer (HORIBA Jobin-Yvon, Edison, NJ) equipped with single photon-counting electronics, double-grating excitation and emission monochromators, automated Glan-Thompson polarizers, and a 450-watt Xenon short arc lamp. Measurements were made either in $4 \times 4-\mathrm{mm}$ quartz microcells or in $1 \times 1-\mathrm{cm}$ quartz cuvettes with a stir disc seated in a thermostated cell holder.

\section{Spectral Measurements of Membrane Electrostatic Potentials}

Measurements of $\Psi_{\mathrm{s}}, \Psi_{\mathrm{d}}$, and $\Delta \Psi_{\mathrm{m}}$ were made with LUVs (80:20 POPC:TOCL), with active mitochondria isolated from $S$. cerevisiae as described (80), or with mitoplasts prepared by osmotic rupture (80), as indicated. $\Psi_{\mathrm{s}}$ measurements were performed as described using the 1,8-ANS reporter probe (18). Briefly, stirred reactions containing $0.95 \mu \mathrm{M}$ 1,8-ANS (added from $10 \mathrm{mM}$ methanol stock) and either LUVs (in $20 \mathrm{mM}$ HEPES-KOH, pH 7.5 with [lipid] eff $=50 \mu \mathrm{M}$ ) or mitoplasts $(0.1 \mathrm{mg} / \mathrm{ml}$ total protein) were titrated with stepwise additions of $10 \mathrm{nmol}$ peptide over $380 \mathrm{~s}$ time course measurements $\left(\lambda_{\mathrm{ex}}=380 \mathrm{~nm} ; \lambda_{\mathrm{em}}=460 \mathrm{~nm}\right) . \Delta \Psi_{\mathrm{m}}$ measurements were performed as described using the TMRM potentiometric probe (18). Briefly, stirred reactions of TMRM assay buffer (20 mM Tris- $\mathrm{HCl}$, pH 7.5, 20 mM KCl, $3 \mathrm{mM} \mathrm{MgCl}_{2}, 4 \mathrm{mM} \mathrm{KH}_{2} \mathrm{PO}_{4}, 250 \mathrm{mM}$ sucrose, $0.5 \%(\mathrm{w} / \mathrm{v})$ fatty acid-free BSA), respiratory substrate (2 mM NADH), and $0.1 \mu \mathrm{M}$ TMRM (added from $10 \mu \mathrm{M}$ stock) were supplemented with mitochondria $(0.1 \mu \mathrm{g} / \mathrm{ml}$ total protein) that were pre-incubated with or without $10 \mu \mathrm{M}$ of peptide, followed by potential dissipation with $2.5 \mu \mathrm{M}$ valinomycin over $240 \mathrm{~s}$ time course measurements $\left(\lambda_{\mathrm{ex}}=546 \mathrm{~nm} ; \lambda_{\mathrm{em}}=573 \mathrm{~nm}\right) . \Psi_{\mathrm{d}}$ measurements were performed as described using the di-8-ANEPPS reporter probe as described (46). Briefly, LUVs were prepared by adding $1 \mathrm{~mol} \%$ di-8-ANEPPS (from ethanol stock) to phospholipids prior to drying lipid films under nitrogen gas, hydration and extrusion. Solutions with di-8-ANEPPS-containing LUVs (in $20 \mathrm{mM}$ HEPES-KOH, $\mathrm{pH} 7.5$ with $_{\text {[lipid] }}^{\text {eff }}=100 \mu \mathrm{M}$ ) were titrated with peptide at the indicated peptide:lipid molar ratios and read by excitation scans $\left(\lambda_{\mathrm{ex}}=\right.$ 
$380-580 \mathrm{~nm} ; \lambda_{\mathrm{em}}=573 \mathrm{~nm} ; 1 \mathrm{~nm}$ increments and $1 \mathrm{~s}$ integration times), from which the ratiometric value ( $R$, emission resulting $420 \mathrm{~nm}: 520 \mathrm{~nm}$ excitation) was used as a readout of $\Psi_{\mathrm{d}}$.

\section{MD simulations}

A similar approach was used as described previously (Mitchell et al., 2020) where the SS31 peptide structure was generated by modifying an extended tetrapeptide with the sequence Arg-Tyr-Lys-Phe. Coordinates were modified using the VMD Molefacture Plugin (81) to invert the stereochemistry of the N-terminal Arg residue from $L$ to $D$ and to replace the 2' and 6' hydrogen atoms of the Tyr side chain with methyl groups. Parameters for the $2^{\prime}, 6^{\prime}$-Dmt were modeled after the parameters of $3^{\prime}, 5^{\prime}$-dimethylphenol after running its structure through ParamChem's CGenFF server (82). Since our initial parameterization of SS-31 (18), CHARMM36m forcefield parameters for cation- $\pi$ interactions have been developed. We have included cation-m terms for SS-31 and other peptide analogs to more accurately model interactions between aromatic side chains and choline head groups found in the bilayer interfacial region.

Tetrapeptides with amino acid sequences matching SS-20 (Phe-Arg-Phe-Lys), SPN4 (Arg-Tyr-Lys-Phe), and SPN10 (Trp-Arg-Trp-Lys) SS peptide analogs were initially generated with proper stereochemistry using the UCSF Chimera Build Structure Plugin (83). CHARMM-GUI was then used to amidate each peptide's C-terminus, obtain CHARMM36m forcefield parameters with cation- $\pi$ interactions enabled for aromatic residues (84-88), solvate each system with TIP3P water model and a $150 \mathrm{mM} \mathrm{NaCl}$ concentration, and generate simulation input files. Following the CHARMM-GUI standard protocol for solvated proteins, the peptide systems were energyminimized using the steepest-descent algorithm for 5000 steps, followed by canonical (NVT) ensemble equilibration for 250 ps with a 1 fs timestep. All minimization, equilibration, and production simulations were performed using the GROMACS version 2019 (33, 34). These minimized and equilibrated structures of SS-20, SPN4, and SPN10 were used in our peptidebilayer systems.

MD simulations were then used to characterize the binding process of the four peptide analogs and to investigate their respective effects on membrane structure and dynamics. All-atom systems with explicit membrane and solvent were prepared using CHARMM-GUI with the CHARMM-36m forcefield and the TIP3P water model $(84-86,88,89)$. Bilayers were generated with TOCL and POPC lipids at a molar ratio of 20:80 TOCL: POPC. Each system contained a total of 150 lipids (75 per leaflet). Peptide-bilayer systems were constructed by removing solvent from the bilayer systems generated by CHARMM-GUI, resizing the box's Z-dimension to $16 \mathrm{~nm}$, 
placing 20 peptides (10 peptides on either side) 2-3 $\mathrm{nm}$ away from the bilayer's headgroup region, and then re-solvating to $\sim 75 \%$ water by mass, and raising the salt concentration to $100 \mathrm{mM} \mathrm{NaCl}$. Each system contained $\sim 93,000$ atoms. A representation of the initial setup of the peptide-bilayer systems is shown in Fig. 4A. Following the CHARMM-GUI standard protocol for protein-bilayer systems, all systems were energy minimized for 5000 steepest descent steps, followed by canonical ensemble (NVT) equilibration for 100 ps with a 1 fs timestep, 200 ps of NPT equilibration with a $1 \mathrm{fs}$ timestep, and $\sim 100$ ns of NPT equilibration with a 2 fs timestep. The NPT equilibration steps were performed with semi-isotropic pressure coupling and the Berendsen barostat and the Berendsen thermostat. Position and dihedral restraints were used during equilibration on the lipids and peptides to maintain lipid geometry and bilayer morphology and to prevent the peptides from interacting with the bilayers during equilibration. To enforce an equal number of peptides interacting with each side of the bilayer (10 peptides per leaflet; 7.5:1 lipid-to-peptide ratio and a 1.5:1 cardiolipin-to-peptide ratio), two inverted flat-bottom restraints in the Z-direction were placed at the bottom of the box $(Z=0 \mathrm{~nm})$. A restraint was placed on the peptides' $C \alpha$ atoms with a force constant of $200 \mathrm{~kJ} \mathrm{~mol}^{-1} \mathrm{~nm}^{-1}$ and a radius of $3 \mathrm{~nm}$, which served to maintain a constant lipid-topeptide ratio on either side of the bilayer. A second restraint was placed on the POPC phosphates with a force constant of $50 \mathrm{~kJ} \mathrm{~mol}^{-1} \mathrm{~nm}^{-1}$ and a radius of $4.5 \mathrm{~nm}$ to prevent the upper and lower leaflet from drifting in the z-direction, while still allowing for natural membrane deformations.

Production simulations were run for $2 \mu \mathrm{s}$ and saved every $1 \mathrm{ps}$. In all production simulations electrostatic and Lennard-Jones (LJ) interactions were cut off at $1.2 \mathrm{~nm}$, with electrostatics shifted from $0 \mathrm{~nm}$ to the cutoff, and LJ interactions shifted from $1.0 \mathrm{~nm}$ to the cutoff. Long-range electrostatic interactions were computed using the particle mesh Ewald method and a fourier spacing of $0.12 \mathrm{~nm}$. All bilayer system production runs were simulated in the NPT ensemble using the Nose-Hoover thermostat, Parrinello-Rahman barostat, and semi-isotropic coupling scheme, with the temperature maintained at $303.15 \mathrm{~K}$ and pressure kept at 1.0 bar with semi-isotropic coupling. The time constants for pressure and temperature coupling were 5.0 and $1.0 \mathrm{ps}$, respectively, and the compressibility value was $4.5 \mathrm{E}-5 \mathrm{bar}^{-1}$. Simulations were performed using periodic boundary conditions in all dimensions and the simulation time step was 2 fs.

Following the $2 \mu$ s unrestrained production simulations additional $1 \mu$ s simulations were performed using NMR-derived NOE distance-restraints. Only those NOE restraints between residues $i$ to $i+2$ and $i$ to $i+3$ NOEs were imposed in the MD simulations. By only including "longrange" restraints we aimed to enforce the long-distance NOEs while still allowing for natural dynamics and not over-restraining the ensemble. A force constant of $5000 \mathrm{~kJ} \mathrm{~mol}^{-1} \mathrm{~nm}^{-1}$ was applied equally to each peptide (to promote sampling of more conformations) and averaged over 
the ensemble of 20 peptides. Since distance restraints based on instantaneous distances can heavily reduce conformational dynamics, the 20 peptides were restrained to a time-averaged distance with a decay time of $10 \mathrm{ps}$. The initial configuration for the NMR-restrained simulations was the final configuration of the $2 \mu \mathrm{s}$ unrestrained simulations. An example .mdp file for the 20peptide system with NOE restraints is included in the supporting information.

Simulations of single peptides in solution were also performed. The initial peptide structures were taken from the top structure in the NMR ensemble obtained in this study. The systems were solvated with the TIP3P water model and $100 \mathrm{mM} \mathrm{NaCl}$ salt concentration. These solvated systems were energy-minimized using the steepest-descent algorithm for 50000 steps (or a maximum force tolerance of $1000 \mathrm{~kJ} \mathrm{~mol}^{-1} \mathrm{~nm}^{-1}$ ), followed by canonical ensemble equilibration for 100 ps with 2 fs timestep, and 100 ps of NPT equilibration with a 2 fs timestep accomplished using the Parrinello-Rahman pressure coupling scheme and the V-rescale thermostat (90). Production simulations for each analog were run for 200 ns with a 2 fs timestep in an NPT ensemble using the Parrinello-Rahman pressure coupling scheme and the V-rescale thermostat.

\section{Analysis of MD simulations}

The binding time-dependence, membrane insertion depth, and bilayer thickness were analyzed using the MDTraj Python module (91) to process the trajectories and in-house scripts using the NumPy $(92,93)$, SciPy (94), and Pandas (95) Python modules to perform calculations.

Average structures $\left(\mathrm{S}_{\mathrm{avg}}\right.$ ) were calculated using the $\mathrm{gmx}$ rmsf function in GROMACS for each of the five conditions (Fig. 1C) according to the following: one $S_{\text {avg }}$ from 20 lead structures (both NMR conditions), one $S_{\text {avg }}$ for each of the 20 peptides (MD: Membrane, 1-2 $\mu$ s time range; MD: Membrane (restrained) 2-3 $\mu$ s), and one $S_{\text {avg }}$ for $13 \times 15$ ns intervals of the trajectory (MD: Solution; block averaging, see Fig. S17) $(33,34)$. The RMSD of the heavy atoms to their respective $S_{\text {avg }}$ was calculated for each condition's corresponding ensemble of peptide structures. The radius of gyration $\left(R_{g}\right)$ was calculated using the gmx gyrate function in GROMACS for the ensembles in each condition described above $(33,34)$.

NOE violations were calculated using in-house Python scripts that accounted for ensemble and time averaging (33-35). The instantaneous ensemble averaged distance $\left(r^{*}(t)\right)$ was computed according to equation 1

$$
r^{*}(t)=\left[\frac{1}{20} \sum_{i=1}^{20} r_{i}(t)^{-6}\right]^{-1 / 6} \text { eq. } 1
$$


Time averaging was then performed according to equation 2

$$
\overline{r^{*}(t)}=\left[\frac{1}{\tau / \Delta t} \sum_{j=t}^{t+\tau / \Delta t} r^{*}(j)^{-3}\right]^{-1 / 3} \quad \text { eq. } 2
$$

where $\tau=10 \mathrm{ps}$, and $\Delta \mathrm{t}=1 \mathrm{ps}$. Violations were determined as those time- and ensemble- averaged pair distances which exceeded the experimentally determined upper bound NOE distances plus a buffer tolerance of $0.3 \mathrm{~A}$. The list of NOEs implemented in the MD simulations and the fraction of time spent in violation of the upper bound for each NOE in each analog are presented in Fig. S10.

Solvent accessible surface area (SASA) measurements were calculated using the gmx sasa function in GROMACS $(33,34)$, which uses the double cubic lattice method (96). For the SASA analyses, we defined the acyl chain region of a lipid as the carbon and hydrogen atoms below the ester carbon. The area per lipid was derived from the gmx energy function in GROMACS $(33,34)$, which outputs the change in the $X-Y$ box dimensions over time; the latter measurement was divided by the number of lipids in one leaflet (75 lipids). The RMSD of each simulated peptide analog in solution with reference to its initial structure was calculated using the gmx rms function in GROMACS $(33,34)$. Individual peptides were used as independent samples for calculating variance in the analysis of peptide-membrane MD simulations and the NMR RMSD and $\mathrm{R}_{g}$ measurements in Fig. 1C. Block averaging (97) was used to select decorrelated time intervals (Fig. S17) and calculate the standard deviation for all SASA measurements (Fig. 4D), bilayer thickness, area per lipid, and RMSD/R from MD simulations of a single peptide in solution. All images of the systems were created using VMD (81). All figures were created using the Matplotlib Python module (98).

\section{NMR sample preparation}

For studies on the free peptides, samples were $10 \mathrm{mM}$ in peptide at $\mathrm{pH} 6$. For studies on the bicelle-bound peptides, bicelles were prepared according to a published method (4). The lipids DHPC, POPC, and TOCL were mixed at concentrations of $4.5,1.5$, and $0.15 \mu$ moles, respectively, followed by drying under nitrogen gas for 20 minutes. After vacuum desiccation overnight, the dry lipid films were resuspended in $1 \mathrm{~mL}$ of de-ionized water, incubated at room temperature for 30 
minutes, and gently swirled into solution. The peptides were added to the bicelles at a molar ratio of 5 peptide to 1 cardiolipin (TOCL), and the $\mathrm{pH}$ was adjusted to 5.5 with potassium hydroxide.

\section{NMR spectroscopy}

NMR experiments were performed on a $600 \mathrm{MHz}$ instrument equipped with a cryogenic probe. NMR assignments for the free peptides were obtained from 2D TOCSY $\left(t_{m}=70 \mathrm{~ms}\right)$, ROESY $\left(t_{m}=200 \mathrm{~ms}\right)$, and NOESY $\left(t_{m}=150 \mathrm{~ms}\right)$ spectra, where $t_{m}$ is the mixing time. These were supplemented with ${ }^{13} \mathrm{C}-\mathrm{HSQC}$ and ${ }^{15} \mathrm{~N}-\mathrm{HSQC}$ spectra obtained for the peptides at natural isotope abundance. All data were obtained at a sample temperature of $25^{\circ} \mathrm{C}$ Assignments for all four peptides are given in Table S1. Chemical shift deviations from random coil values (99) were used to infer cation-pi interactions. NMR structures of the free peptides were calculated using distance restraints obtained from ROESY spectra with $t_{m}=200 \mathrm{~ms}$. For transferred NOE experiments, the free and bound peptides are in fast exchange and trNOE experiments were performed on samples that had an excess of peptide (4). Consequently, chemical shifts in the presence and absence of bicelles are highly similar, and NMR assignments could be readily transferred between the two types of samples. Lipid resonances were assigned from the literature (36) and are summarized in Fig. S11. The trNOE correlations for NMR structure calculations were obtained from 2D-NOESY $\left(t_{m}=150 \mathrm{~ms}\right)$ experiments. The optimal $t_{m}$ value was chosen from the linear portion of a NOE buildup curve (Fig. S18), to minimize spin diffusion effects $(32,100)$.

\section{NMR structure calculation and analysis}

Quantification of NOESY peak intensities and NMR structure calculations were done with the programs CCPN Analysis (101) and Xplor-NIH (102), respectively, on the NMRbox platform (103). The input data for NMR structure calculations were ROE (free peptide) or trNOE distance constraints (bound peptide), together with broad dihedral restraints of $\varphi=-90 \pm 70^{\circ}, \Psi=60 \pm 120^{\circ}$ to maintain backbone torsional angles of the two central residues in common regions of Ramachandran space. NMR structures were calculated using simulated annealing and refinement protocols starting from 80 initial conformers with random backbone $\varphi, \psi$ dihedral angles. For each peptide, the 20 lowest energy structures with no violations outside the thresholds specified in Tables $\mathbf{S 2}$ and $\mathbf{S 3}$ were kept for analysis. Structure \#1 in the resulting NMR structure bundles is the closest to the ensemble mean. Electrostatic surfaces for membrane-bound peptides were calculated with the APBS program (104).

Least squares structure superpositions of the NMR bundles were calculated with the FIT routine of the program MolMol (105). To estimate the limiting maximum RMSD for tetrapeptides 
with unrelated structures we used two approaches. In the first, we randomly extracted 10 tetrapeptide fragments from high-resolution protein structures in the PDB. The backbone RMSD was $\sim 1 \AA$, while the heavy atom RMSD could not be calculated because of different side chains. In a second approach we calculated SS-peptide structures without any experimental distance or dihedral restraints. We obtained backbone RMSDs of 1 to $2 \AA$, and heavy atom RMSDs of 3 to 5 $\AA$.

\section{Cell culture}

Human renal epithelial cells (HK-2) and human retinal pigment epithelial cells (ARPE-19) were obtained from ATCC. HK-2 cells were cultured in DMEM (Dulbecco's Modified Eagle's Medium) containing $1 \mathrm{~g} / \mathrm{L}$ glucose and $10 \%$ fetal bovine serum (FBS), 100 units $/ \mathrm{ml}$ penicillin, and $100 \mu \mathrm{g} / \mathrm{ml}$ streptomycin. ARPE-19 cells were grown in DMEM/F12 medium containing $1 \mathrm{~g} / \mathrm{L}$ glucose and $10 \%$ fetal bovine serum (FBS), 100 units $/ \mathrm{ml}$ penicillin, and $100 \mu \mathrm{g} / \mathrm{ml}$ streptomycin.

\section{Cell uptake and mitochondrial localization of CL-binding peptides}

Cell uptake of SS-31 and SPN10 was determined using N-biotinylated SS-31 and SPN10 and detected by streptavidin binding. After 3 days serum deprivation to deplete endogenous biotin, cells were treated with $1 \mu \mathrm{M}$ biotinylated peptides for $1 \mathrm{~h}$ before they were fixed with $4 \%$ PFA and incubated with Streptavidin-AlexaFluor 594 antibody (Jackson ImmunoResearch, West Grove, PA) and Hoechst 33342 (Novus Biologicals, Centennial, CO). Images were obtained with a Nikon Eclipse Ti2 fluorescent microscope using a 100X objective.

\section{Cell viability and cellular ATP after 7 days serum deprivation}

Cells were seeded in 96 -well culture plates at an initial density of $5 \times 10^{3}$ cells. On the day of the experiment, FBS was removed from the culture medium and cells were incubated in serumfree DMEM alone (control group) or serum-free DMEM containing $10 \mathrm{nM}$ peptide analogs for 7 days. All treatments were carried out with $\mathrm{N}=4-6$ in each experiment. Cell viability was measured by resazurin fluorescence (alamarBlue) from Thermo Fisher (Waltham, MA). ATP was measured using the ApoSENSOR ATP Bioluminescence Assay Kit (BioVision, Milpitas, CA). Luminescence was measured using a microplate reader (SpectraMax iD3, Molecular Devices, San Jose, CA). Results in each experiment were normalized to control and all data are presented as mean \pm SEM from 4 experiments. Differences among groups were compared by one-way ANOVA. Post hoc analyses were carried out using Tukey's multiple comparisons test.

\section{Statistical analyses and scientific rigor}


All means reported represent a minimum of $n=3$ independently prepared sample replicates and are reported as means \pm standard deviation (SD) or standard error of the mean (SEM), as appropriate. Statistical analyses were performed using one-way ANOVAs or Wilcoxon rank sum tests as indicated. Differences among sample populations were considered significant at $P<0.05$.

\section{Acknowledgements}

This work was supported by the National Institutes of Health (Grant R01-AG065879 to N.N.A. and Grant R35-GM119762 to E.R.M.), by The Barth Syndrome Foundation (2020 Idea Grant to N.N.A.) and by a charitable contribution from the Social Profit Network (to N.N.A.)

\section{Conflict of Interest}

Coauthor H.H.S. is the inventor of the mitochondria-targeted peptides described in this article, and the Founder of Stealth Biotherapeutics, a clinical stage biopharmaceutical company that licensed this peptide technology from the Cornell Research Foundation for research and development. H.H.S. does not currently hold any position in Stealth Biotherapeutics but has financial interests in the company. 


\section{Figure Legends}

Figure 1. Peptide structures and membrane-driven peptide folding. A) Peptide sequences and chemical structures. Upper series, peptide sequences aligned with respect to basic and aromatic side chains; lower series, chemical structures of peptides. Basic and aromatic groups are shown in teal and orange, respectively. B) NMR structures of peptides in solution. The top 20 lowest-energy NMR conformers obtained by ROESY analysis. The main chain atoms are colored by type (carbon, white; oxygen, red; nitrogen, blue); basic and aromatic side chains are colored in teal and orange, respectively. C) Comparison of peptide conformational variance in NMR and MD assemblies. Radius of gyration $\left(R_{g}\right)$ and root mean square deviation (RMSD) to the average peptide structure calculated for NMR structures in solution (black squares) and in the presence of a membrane (red squares), and for MD simulations of peptides in solution (black circles), in the presence of a lipid bilayer conducted without (red circles), and with (cyan circles) NOE restraints. Measurements of individual peptides $(n=20)$ are shown as small symbols, with ensemble averages and error bars (SD) shown as larger symbols. Corresponding values for the $\mathrm{R}_{g}$ and RMSD measurements are in Supplementary Table S4.

Figure 2. Microcalorimetry of peptide binding to LUVs. A) Equilibrium binding isotherms. Wiseman plots showing blank-corrected average integrated heats for lipid-into-peptide titrations as a function of [lipid] ${ }^{\text {eff }}$ :[peptide] molar ratio using LUVs composed of an 80:20 molar ratio of POPC:TOCL with peptides color-coded as shown. Points represent means ( $n \geq 3 \pm S D$ ) and curve fits are to binding models of single, independent sites. B) Comparison of binding parameters. Values of equilibrium binding parameters calculated from curve fits are shown for peptides colorcoded as in Panel A. Statistical comparisons represent one-way ANOVA with Tukey's multiple comparison test $(\alpha=0.05)$, with differences representing a comparison to SS-31 (no symbol, $P>$ $0.05 ; \cdot P \leq 0.05 ; \bullet P \leq 0.01 ; \cdots P \leq 0.001)$.

Figure 3. Peptide structures in the bicelle-bound state. A) Top 20 lowest energy NMR conformers. Backbone atoms and side chains are color coded as in Fig 1B. B) Peptide secondary structure. Conformations closest to NMR ensemble means are shown. Backbones are shown in ball-and-stick representation, $\mathrm{H}$-bonds are shown as dotted lines, and side chains are shown as lines (orange for aromatic, teal for basic). Three of the peptides have main chain $\mathrm{H}$-bonds: SPN10 [CO(1) to $\mathrm{NH}(4)]$, SS-20 $[\mathrm{CO}(1)$ to $\mathrm{NH}(4)]$, and SPN4 $\left[\mathrm{CO}(2)\right.$ to $\left.\mathrm{NH}_{2}(5)\right]$. SS-31 is extended and has no $\mathrm{H}$-bonds.

Figure 4. MD simulations of peptide conformations and membrane interactions. A) Snapshot of a typical MD simulation. Peptides (red) are shown in the aqueous phase on either side of a bilayer composed of an 80:20 molar ratio of POPC:TOCL (lipid acyl chains in wireframe, and lipid phosphates shown as blue van der Waals spheres. B) Comparison of NMR and MD structures. Comparison of the simulation time spent by each peptide analog below a heavy atom RMSD of $3 \AA$ to their respective lead NMR membrane-bound structures before (b/ue) and after $(r e d)$ NOE restraints were imposed. C) Average membrane insertion depths. Bilayer depth ( $Z^{\text {pos }}, n=20 \pm 95 \% \mathrm{Cl}$ ) for $\mathrm{C}^{\beta}$ atoms on each residue for each peptide shown in comparison with the average $Z^{\text {pos }}$ levels of lipid headgroup phosphates (dashed blue) and lipid ester carbons (dashed red). The positions of the lipid atoms were averaged between the four different peptide systems for consistent comparison. The depths represent normalized distances to the bilayer COM. D) Peptide-dependent SASA during MD trajectories. SASA of the total bilayer and peptides system (Total) and individual components (Headgroup, Acyl chain, and Peptide) calculated from MD trajectories in the absence of peptide or with the peptide analogs indicated. Open symbols show individual block-averaged datapoints from each trajectory; solid symbols and 
error bars show means and SD for each dataset. Statistical comparisons are based on the Wilcoxon rank sum test, with differences representing a comparison to the No-peptide control, or to SS-31 as indicated (no symbol, $P>0.05 ; \cdot P \leq 0.05 ; \cdot P \leq 0.01 ; \cdots P \leq 0.001$ ).

Figure 5. Effects of peptides on membrane electrostatic potentials. A,B) Effects on surface potential $\left(\Psi_{\mathrm{s}}\right)$. Left, signal-averaged time courses of $1,8-\mathrm{ANS}$ emission with addition of $(\mathrm{A})$ mitoplasts (generated from Saccharomyces cerevisiae mitochondria, $200 \mu \mathrm{g}$ total protein) or (B) 80:20 POPC:TOCL LUVs (100 nmol lipideff), shown by gray arrowheads ("MP" and "LUV", respectively), followed by sequential addition of peptide (10 nmol each), shown by black arrowheads. Right, saturation binding curves taken from 1,8-ANS time course data. C) Effects on dipole potential $\left(\Psi_{\mathrm{d}}\right)$. Left, profile of di-8-ANEPPS measurements $(R$, ratio of $670 \mathrm{~nm}$ emission from $420 \mathrm{~nm}$ and $520 \mathrm{~nm}$ excitation peaks) in the presence of 80:20 POPC:TOCL LUVs (25 nmol lipid ${ }^{\text {eff }}$. Right, saturation binding curves taken from ratiometric di-8-ANEPPS measurements. D) Effects on transmembrane potential $\left(\Delta \boldsymbol{\Psi}_{\mathrm{m}}\right)$. Left, signal-averaged time course profiles of TMRM emission with addition of mitochondria from S. cerevisiae $(200 \mu \mathrm{g}$ total protein) following preincubation with $10 \mu \mathrm{M}$ of respective peptide (gray arrowhead, "Mito") and addition of ionophore valinomycin (black arrowhead, "Val"). Right, fractional change in TMRM emission following mitochondria addition. All means and traces are from $n=3$ independent samples and all error bars indicate SD. Control, addition of peptide buffer vehicle only.

Figure 6. Cellular localization and efficacy of mitochondria-targeted peptides in cell culture. A) Intracellular localization of peptides. Confocal microscopy images of N-biotinylated variants of SS-31 and SPN10 in HK-2 and ARPE-19 cells as indicated. Biotin was visualized with streptavidin-AlexaFluor 594 and cell nuclei were stained with Hoechst 33342. B,C) Peptidedependent restoration of viability and energy metabolism in cell culture stress models. HK2 and ARPE-19 cells, as indicated, subjected to $7 \mathrm{~d}$ of serum deprivation in the absence or presence of mitochondria-targeted peptides (10 nM) showed peptide-dependent increase in B) cell viability, and in C) cellular ATP levels. Statistical comparisons represent one-way ANOVA with Tukey's multiple comparison test, with differences representing a comparison to vehicle-only control $(\bullet P \leq 0.01 ; \cdots P \leq 0.0001)$ or comparison to SS-31 treatment $(\# P \leq 0.05 ; \S P \leq 0.001)$. 


\section{$\underline{\text { References }}$}

1. Zhao K, Luo G, Giannelli S, Szeto HH. Mitochondria-targeted peptide prevents mitochondrial depolarization and apoptosis induced by tert-butyl hydroperoxide in neuronal cell lines. Biochem Pharmacol. 2005;70(12):1796-806. Epub 2005/10/12. doi: 10.1016/j.bcp.2005.08.022. PubMed PMID: 16216225.

2. Zhao K, Luo G, Zhao GM, Schiller PW, Szeto HH. Transcellular transport of a highly polar 3+ net charge opioid tetrapeptide. J Pharmacol Exp Ther. 2003;304(1):425-32. Epub 2002/12/20. doi: 10.1124/jpet.102.040147. PubMed PMID: 12490619.

3. Zhao K, Zhao GM, Wu D, Soong Y, Birk AV, Schiller PW, Szeto HH. Cell-permeable peptide antioxidants targeted to inner mitochondrial membrane inhibit mitochondrial swelling, oxidative cell death, and reperfusion injury. J Biol Chem. 2004;279(33):34682-90. Epub 2004/06/05. doi: 10.1074/jbc.M402999200. PubMed PMID: 15178689.

4. $\quad$ Birk AV, Chao WM, Bracken C, Warren JD, Szeto HH. Targeting mitochondrial cardiolipin and the cytochrome c/cardiolipin complex to promote electron transport and optimize mitochondrial ATP synthesis. Br J Pharmacol. 2014;171(8):2017-28. Epub 2013/10/19. doi: 10.1111/bph.12468. PubMed PMID: 24134698; PMCID: PMC3976619.

5. $\quad$ Birk AV, Liu S, Soong Y, Mills W, Singh P, Warren JD, Seshan SV, Pardee JD, Szeto $\mathrm{HH}$. The mitochondrial-targeted compound SS-31 re-energizes ischemic mitochondria by interacting with cardiolipin. J Am Soc Nephrol. 2013;24(8):1250-61. Epub 2013/07/03. doi: 10.1681/ASN.2012121216. PubMed PMID: 23813215; PMCID: PMC3736700.

6. Siegel MP, Kruse SE, Percival JM, Goh J, White CC, Hopkins HC, Kavanagh TJ, Szeto $\mathrm{HH}$, Rabinovitch PS, Marcinek DJ. Mitochondrial-targeted peptide rapidly improves mitochondrial energetics and skeletal muscle performance in aged mice. Aging Cell. 2013;12(5):763-71. Epub 2013/05/23. doi: 10.1111/acel.12102. PubMed PMID: 23692570; PMCID: PMC3772966.

7. Anderson EJ, Lustig ME, Boyle KE, Woodlief TL, Kane DA, Lin CT, Price JW, 3rd, Kang L, Rabinovitch PS, Szeto HH, Houmard JA, Cortright RN, Wasserman DH, Neufer PD. Mitochondrial $\mathrm{H} 2 \mathrm{O} 2$ emission and cellular redox state link excess fat intake to insulin resistance in both rodents and humans. J Clin Invest. 2009;119(3):573-81. Epub 2009/02/04. doi: 10.1172/JCI37048. PubMed PMID: 19188683; PMCID: PMC2648700.

8. Allen ME, Pennington ER, Perry JB, Dadoo S, Makrecka-Kuka M, Dambrova M, Moukdar F, Patel HD, Han X, Kidd GK, Benson EK, Raisch TB, Poelzing S, Brown DA, Shaikh $\mathrm{SR}$. The cardiolipin-binding peptide elamipretide mitigates fragmentation of cristae networks following cardiac ischemia reperfusion in rats. Commun Biol. 2020;3(1):389. Epub 2020/07/19. doi: 10.1038/s42003-020-1101-3. PubMed PMID: 32680996; PMCID: PMC7368046.

9. Campbell MD, Duan J, Samuelson AT, Gaffrey MJ, Merrihew GE, Egertson JD, Wang L, Bammler TK, Moore RJ, White CC, Kavanagh TJ, Voss JG, Szeto HH, Rabinovitch PS, MacCoss MJ, Qian WJ, Marcinek DJ. Improving mitochondrial function with SS-31 reverses age-related redox stress and improves exercise tolerance in aged mice. Free Radic Biol Med. 2019;134:268-81. Epub 2019/01/01. doi: 10.1016/j.freeradbiomed.2018.12.031. PubMed PMID: 30597195; PMCID: PMC6588449.

10. Szeto HH. Stealth Peptides Target Cellular Powerhouses to Fight Rare and Common Age-Related Diseases. Protein Pept Lett. 2018;25(12):1108-23. Epub 2018/11/02. doi: 10.2174/0929866525666181101105209. PubMed PMID: 30381054.

11. Zhang H, Alder NN, Wang W, Szeto H, Marcinek DJ, Rabinovitch PS. Reduction of elevated proton leak rejuvenates mitochondria in the aged cardiomyocyte. Elife. 2020;9. Epub 2020/12/16. doi: 10.7554/eLife.60827. PubMed PMID: 33319746; PMCID: PMC7738186.

12. Zhao H, Li H, Hao S, Chen J, Wu J, Song C, Zhang M, Qiao T, Li K. Peptide SS-31 upregulates frataxin expression and improves the quality of mitochondria: implications in the 
treatment of Friedreich ataxia. Sci Rep. 2017;7(1):9840. Epub 2017/08/31. doi: 10.1038/s41598017-10320-2. PubMed PMID: 28852135; PMCID: PMC5575096.

13. Reid Thompson W, Hornby B, Manuel R, Bradley E, Laux J, Carr J, Vernon HJ. A phase $2 / 3$ randomized clinical trial followed by an open-label extension to evaluate the effectiveness of elamipretide in Barth syndrome, a genetic disorder of mitochondrial cardiolipin metabolism. Genet Med. 2021;23(3):471-8. Epub 2020/10/21. doi: 10.1038/s41436-020-01006-8. PubMed PMID: 33077895; PMCID: PMC7935714.

14. Roshanravan B, Liu SZ, Ali AS, Shankland EG, Goss C, Amory JK, Robertson HT, Marcinek DJ, Conley KE. In vivo mitochondrial ATP production is improved in older adult skeletal muscle after a single dose of elamipretide in a randomized trial. PLoS One. 2021;16(7):e0253849. Epub 2021/07/16. doi: 10.1371/journal.pone.0253849. PubMed PMID: 34264994; PMCID: PMC8282018 Conley, and David Marcinek served as paid consultants for Stealth BioTherapeutics from 2014-2016. The authors worked with Stealth BioTherapeutics on the design of this study. Otherwise, the funders played no role in data collection and analysis nor the decision to publish this manuscript. These competing interests do not alter our adherence to PLOS ONE policies on sharing data and materials.

15. Birk AV, Chao WM, Liu S, Soong Y, Szeto HH. Disruption of cytochrome c heme coordination is responsible for mitochondrial injury during ischemia. Biochim Biophys Acta. 2015;1847(10):1075-84. Epub 2015/06/14. doi: 10.1016/j.bbabio.2015.06.006. PubMed PMID: 26071084; PMCID: PMC4547887.

16. Paradies G, Paradies V, Ruggiero FM, Petrosillo G. Role of Cardiolipin in Mitochondrial Function and Dynamics in Health and Disease: Molecular and Pharmacological Aspects. Cells. 2019;8(7). Epub 2019/07/19. doi: 10.3390/cells8070728. PubMed PMID: 31315173; PMCID: PMC6678812.

17. Szeto HH, Liu S. Cardiolipin-targeted peptides rejuvenate mitochondrial function, remodel mitochondria, and promote tissue regeneration during aging. Arch Biochem Biophys. 2018;660:137-48. Epub 2018/10/26. doi: 10.1016/j.abb.2018.10.013. PubMed PMID: 30359579. 18. Mitchell W, Ng EA, Tamucci JD, Boyd KJ, Sathappa M, Coscia A, Pan M, Han X, Eddy NA, May ER, Szeto HH, Alder NN. The mitochondria-targeted peptide SS-31 binds lipid bilayers and modulates surface electrostatics as a key component of its mechanism of action. J Biol Chem. 2020;295(21):7452-69. Epub 2020/04/11. doi: 10.1074/jbc.RA119.012094. PubMed PMID: 32273339; PMCID: PMC7247319.

19. Chavez JD, Tang X, Campbell MD, Reyes G, Kramer PA, Stuppard R, Keller A, Zhang $H$, Rabinovitch PS, Marcinek DJ, Bruce JE. Mitochondrial protein interaction landscape of SS31. Proc Natl Acad Sci U S A. 2020;117(26):15363-73. Epub 2020/06/20. doi: 10.1073/pnas.2002250117. PubMed PMID: 32554501 ; PMCID: PMC7334473.

20. McDonald SK, Fleming KG. Aromatic Side Chain Water-to-Lipid Transfer Free Energies Show a Depth Dependence across the Membrane Normal. J Am Chem Soc. 2016;138(25):7946-50. Epub 2016/06/03. doi: 10.1021/jacs.6b03460. PubMed PMID: 27254476; PMCID: PMC4927395.

21. Jiang Q, Yin J, Chen J, Ma X, Wu M, Liu G, Yao K, Tan B, Yin Y. Mitochondria-Targeted Antioxidants: A Step towards Disease Treatment. Oxid Med Cell Longev. 2020;2020:8837893. Epub 2020/12/24. doi: 10.1155/2020/8837893. PubMed PMID: 33354280; PMCID: PMC7735836.

22. Cho J, Won K, Wu D, Soong Y, Liu S, Szeto HH, Hong MK. Potent mitochondriatargeted peptides reduce myocardial infarction in rats. Coron Artery Dis. 2007;18(3):215-20. Epub 2007/04/13. doi: 10.1097/01.mca.0000236285.71683.b6. PubMed PMID: 17429296. 23. Szeto HH, Liu S, Soong Y, Birk AV. Improving mitochondrial bioenergetics under ischemic conditions increases warm ischemia tolerance in the kidney. Am J Physiol Renal Physiol. 2015;308(1):F11-21. Epub 2014/10/24. doi: 10.1152/ajprenal.00366.2014. PubMed PMID: 25339695. 
24. Yang L, Zhao K, Calingasan NY, Luo G, Szeto HH, Beal MF. Mitochondria targeted peptides protect against 1-methyl-4-phenyl-1,2,3,6-tetrahydropyridine neurotoxicity. Antioxid Redox Signal. 2009;11(9):2095-104. Epub 2009/02/11. doi: 10.1089/ARS.2009.2445. PubMed PMID: 19203217; PMCID: PMC2819801.

25. Avci FG, Akbulut BS, Ozkirimli E. Membrane Active Peptides and Their Biophysical Characterization. Biomolecules. 2018;8(3). Epub 2018/08/24. doi: 10.3390/biom8030077. PubMed PMID: 30135402; PMCID: PMC6164437.

26. Kabelka I, Vacha R. Advances in Molecular Understanding of alpha-Helical MembraneActive Peptides. Acc Chem Res. 2021;54(9):2196-204. Epub 2021/04/13. doi:

10.1021/acs.accounts.1c00047. PubMed PMID: 33844916.

27. Jas GS, Vallejo-Calzada R, Johnson CK, Kuczera K. Dynamic elements and kinetics: Most favorable conformations of peptides in solution with measurements and simulations. J Chem Phys. 2019;151(22):225102. Epub 2019/12/16. doi: 10.1063/1.5131782. PubMed PMID: 31837693.

28. Williamson MP. Applications of the NOE in Molecular Biology. In: Webb GA, editor. Annual Reports on NMR Spectroscopy2009. p. 77-109.

29. Neri D, Billeter M, Wider G, Wuthrich K. NMR determination of residual structure in a urea-denatured protein, the 434-repressor. Science. 1992;257(5076):1559-63. Epub 1992/09/11. doi: 10.1126/science.1523410. PubMed PMID: 1523410.

30. Smith LJ, Alexandrescu AT, Pitkeathly M, Dobson CM. Solution structure of a peptide fragment of human alpha-lactalbumin in trifluoroethanol: a model for local structure in the molten globule. Structure. 1994;2(8):703-12. Epub 1994/08/15. doi: 10.1016/s0969-2126(00)00071-x. PubMed PMID: 7994570.

31. Seelig J. Thermodynamics of lipid-peptide interactions. Biochim Biophys Acta. 2004;1666(1-2):40-50. Epub 2004/11/03. doi: 10.1016/j.bbamem.2004.08.004. PubMed PMID: 15519307.

32. Post CB. Exchange-transferred NOE spectroscopy and bound ligand structure determination. Curr Opin Struct Biol. 2003;13(5):581-8. Epub 2003/10/22. doi: 10.1016/j.sbi.2003.09.012. PubMed PMID: 14568612.

33. Abraham MJ, Murtola T, Schulz R, Pail S, Smith JC, Hess B, Lindahl E. GROMACS: High performance molecular simulations through multi-level parallelism from laptops to supercomputers. SoftwareX. 2015;1-2:19-25.

34. Hess B, Kutzner C, van der Spoel D, Lindahl E. GROMACS 4: Algorithms for highly efficient, load-balanced, and scalable molecular simulation. J Chem Theory Comput. 2008;4:435-47.

35. Hess B, Scheek RM. Orientation restraints in molecular dynamics simulations using time and ensemble averaging. J Magn Reson. 2003;164(1):19-27. Epub 2003/08/23. doi: 10.1016/s1090-7807(03)00178-2. PubMed PMID: 12932451.

36. Liebau J, Ye W, Maler L. Characterization of fast-tumbling isotropic bicelles by PFG diffusion NMR. Magn Reson Chem. 2017;55(5):395-404. Epub 2015/12/15. doi: 10.1002/mrc.4399. PubMed PMID: 26662467.

37. Boyd KJ, Alder NN, May ER. Molecular Dynamics Analysis of Cardiolipin and Monolysocardiolipin on Bilayer Properties. Biophys J. 2018;114(9):2116-27. Epub 2018/05/10. doi: 10.1016/j.bpj.2018.04.001. PubMed PMID: 29742405; PMCID: PMC5961467. 38. Boyd KJ, Alder NN, May ER. Buckling Under Pressure: Curvature-Based Lipid Segregation and Stability Modulation in Cardiolipin-Containing Bilayers. Langmuir. 2017;33(27):6937-46. Epub 2017/06/20. doi: 10.1021/acs.langmuir.7b01185. PubMed PMID: 28628337; PMCID: PMC5654595.

39. Wilson BA, Ramanathan A, Lopez CF. Cardiolipin-Dependent Properties of Model Mitochondrial Membranes from Molecular Simulations. Biophys J. 2019;117(3):429-44. Epub 2019/07/28. doi: 10.1016/j.bpj.2019.06.023. PubMed PMID: 31349988; PMCID: PMC6697365. 
40. Tuchsen E, Jensen MM, Westh P. Solvent accessible surface area (ASA) of simulated phospholipid membranes. Chem Phys Lipids. 2003;123(1):107-16. Epub 2003/03/15. doi: 10.1016/s0009-3084(02)00193-7. PubMed PMID: 12637169.

41. Oshima H. Biophysical Chemistry of Biointerfaces. Hoboken, New Jersey: John Wiley \& Sons, Inc.; 2010.

42. Robertson DE, Rottenberg $\mathrm{H}$. Membrane potential and surface potential in mitochondria. Fluorescence and binding of 1-anilinonaphthalene-8-sulfonate. J Biol Chem. 1983;258(18):11039-48. Epub 1983/09/25. PubMed PMID: 6885812.

43. Gibrat R, Romieu C, Grignon C. A procedure for estimating the surface potential of charged or neutral membranes with 8-anilino-1-naphthalenesulphonate probe. Adequacy of the Gouy-Chapman model. Biochim Biophys Acta. 1983;736(2):196-202. Epub 1983/12/21. doi: 10.1016/0005-2736(83)90284-5. PubMed PMID: 6652083.

44. Wang L. Measurements and implications of the membrane dipole potential. Annu Rev Biochem. 2012;81:615-35. Epub 2012/03/27. doi: 10.1146/annurev-biochem-070110-123033. PubMed PMID: 22443933.

45. Zhan $\mathrm{H}$, Lazaridis $\mathrm{T}$. Influence of the membrane dipole potential on peptide binding to lipid bilayers. Biophys Chem. 2012;161:1-7. Epub 2011/11/22. doi: 10.1016/j.bpc.2011.10.002. PubMed PMID: 22100997; PMCID: PMC3262865.

46. Clarke RJ, Kane DJ. Optical detection of membrane dipole potential: avoidance of fluidity and dye-induced effects. Biochim Biophys Acta. 1997;1323(2):223-39. Epub 1997/01/31. doi: 10.1016/s0005-2736(96)00188-5. PubMed PMID: 9042345.

47. Hollmann A, Matos PM, Augusto MT, Castanho MA, Santos NC. Conjugation of cholesterol to HIV-1 fusion inhibitor C34 increases peptide-membrane interactions potentiating its action. PLoS One. 2013;8(4):e60302. Epub 2013/04/09. doi: 10.1371/journal.pone.0060302. PubMed PMID: 23565220; PMCID: PMC3614957.

48. Mitchell P, Moyle J. Chemiosmotic hypothesis of oxidative phosphorylation. Nature. 1967;213(5072):137-9. Epub 1967/01/14. doi: 10.1038/213137a0. PubMed PMID: 4291593. 49. Scaduto RC, Jr., Grotyohann LW. Measurement of mitochondrial membrane potential using fluorescent rhodamine derivatives. Biophys J. 1999;76(1 Pt 1):469-77. Epub 1999/01/06. doi: 10.1016/S0006-3495(99)77214-0. PubMed PMID: 9876159; PMCID: PMC1302536.

50. Charles I, Khalyfa A, Kumar DM, Krishnamoorthy RR, Roque RS, Cooper N, Agarwal N. Serum deprivation induces apoptotic cell death of transformed rat retinal ganglion cells via mitochondrial signaling pathways. Invest Ophthalmol Vis Sci. 2005;46(4):1330-8. Epub 2005/03/26. doi: 10.1167/iovs.04-0363. PubMed PMID: 15790899.

51. Patten DA, Wong J, Khacho M, Soubannier V, Mailloux RJ, Pilon-Larose K, MacLaurin JG, Park DS, McBride HM, Trinkle-Mulcahy L, Harper ME, Germain M, Slack RS. OPA1dependent cristae modulation is essential for cellular adaptation to metabolic demand. EMBO J. 2014;33(22):2676-91. Epub 2014/10/10. doi: 10.15252/embj.201488349. PubMed PMID: 25298396; PMCID: PMC4282575.

52. Zhu W, Chen J, Cong X, Hu S, Chen X. Hypoxia and serum deprivation-induced apoptosis in mesenchymal stem cells. Stem Cells. 2006;24(2):416-25. Epub 2005/10/29. doi: 10.1634/stemcells.2005-0121. PubMed PMID: 16253984.

53. Hohlweg W, Wagner GE, Hofbauer HF, Sarkleti F, Setz M, Gubensak N, Lichtenegger S, Falsone SF, Wolinski H, Kosol S, Oostenbrink C, Kohlwein SD, Zangger K. A cation-pi interaction in a transmembrane helix of vacuolar ATPase retains the proton-transporting arginine in a hydrophobic environment. J Biol Chem. 2018;293(49):18977-88. Epub 2018/09/14. doi: 10.1074/jbc.RA118.005276. PubMed PMID: 30209131; PMCID: PMC6295739.

54. Infield DT, Rasouli A, Galles GD, Chipot C, Tajkhorshid E, Ahern CA. Cation-pi Interactions and their Functional Roles in Membrane Proteins. J Mol Biol. 2021;433(17):167035. Epub 2021/05/07. doi: 10.1016/j.jmb.2021.167035. PubMed PMID: 33957146; PMCID: PMC8338773. 
55. Reddy PH, Manczak M, Kandimalla R. Mitochondria-targeted small molecule SS31: a potential candidate for the treatment of Alzheimer's disease. Hum Mol Genet. 2017;26(8):148396. Epub 2017/02/12. doi: 10.1093/hmg/ddx052. PubMed PMID: 28186562; PMCID: PMC6075532.

56. Venkatachalam CM. Stereochemical criteria for polypeptides and proteins. V. Conformation of a system of three linked peptide units. Biopolymers. 1968;6(10):1425-36. Epub 1968/10/01. doi: 10.1002/bip.1968.360061006. PubMed PMID: 5685102.

57. Lewis PN, Momany FA, Scheraga HA. Energy parameters in polypeptides. VI. Conformational energy analysis of the $\mathrm{N}$-aceyl N'-methyl amides of the twenty naturally occurring amino acids. Israeli Journal of Chemistry. 1973;11:121-52.

58. Shapovalov M, Vucetic S, Dunbrack RL, Jr. A new clustering and nomenclature for beta turns derived from high-resolution protein structures. PLoS Comput Biol. 2019;15(3):e1006844. Epub 2019/03/08. doi: 10.1371/journal.pcbi.1006844. PubMed PMID: 30845191; PMCID: PMC6424458.

59. Gao J, Bosco DA, Powers ET, Kelly JW. Localized thermodynamic coupling between hydrogen bonding and microenvironment polarity substantially stabilizes proteins. Nat Struct Mol Biol. 2009;16(7):684-90. Epub 2009/06/16. doi: 10.1038/nsmb.1610. PubMed PMID: 19525973; PMCID: PMC2754385.

60. Leftin A, Molugu TR, Job C, Beyer K, Brown MF. Area per lipid and cholesterol interactions in membranes from separated local-field (13)C NMR spectroscopy. Biophys J. 2014;107(10):2274-86. Epub 2014/11/25. doi: 10.1016/j.bpj.2014.07.044. PubMed PMID: 25418296; PMCID: PMC4241443.

61. Capaldi RA. Arrangement of proteins in the mitochondrial inner membrane. Biochim Biophys Acta. 1982;694(3):291-306. Epub 1982/11/30. doi: 10.1016/0304-4157(82)90009-0. PubMed PMID: 6295486.

62. Shinoda W. Permeability across lipid membranes. Biochim Biophys Acta. 2016;1858(10):2254-65. Epub 2016/04/18. doi: 10.1016/j.bbamem.2016.03.032. PubMed PMID: 27085977.

63. Bour A, Kruglik SG, Chabanon M, Rangamani P, Puff N, Bonneau S. Lipid Unsaturation Properties Govern the Sensitivity of Membranes to Photoinduced Oxidative Stress. Biophys J. 2019;116(5):910-20. Epub 2019/02/20. doi: 10.1016/j.bpj.2019.01.033. PubMed PMID: 30777304; PMCID: PMC6401011.

64. Min K, Smuder AJ, Kwon OS, Kavazis AN, Szeto HH, Powers SK. Mitochondrialtargeted antioxidants protect skeletal muscle against immobilization-induced muscle atrophy. J Appl Physiol (1985). 2011;111(5):1459-66. Epub 2011/08/06. doi: 10.1152/japplphysiol.00591.2011. PubMed PMID: 21817113; PMCID: PMC3220313.

65. Yin X, Manczak M, Reddy PH. Mitochondria-targeted molecules MitoQ and SS31 reduce mutant huntingtin-induced mitochondrial toxicity and synaptic damage in Huntington's disease. Hum Mol Genet. 2016;25(9):1739-53. Epub 2016/02/26. doi: 10.1093/hmg/ddw045. PubMed PMID: 26908605; PMCID: PMC4986329.

66. Wu J, Hao S, Sun XR, Zhang H, Li H, Zhao H, Ji MH, Yang JJ, Li K. Elamipretide (SS31) Ameliorates Isoflurane-Induced Long-Term Impairments of Mitochondrial Morphogenesis and Cognition in Developing Rats. Front Cell Neurosci. 2017;11:119. Epub 2017/05/11. doi: 10.3389/fncel.2017.00119. PubMed PMID: 28487636; PMCID: PMC5403826.

67. Ben-Tal N, Honig B, Bagdassarian CK, Ben-Shaul A. Association entropy in adsorption processes. Biophys J. 2000;79(3):1180-7. Epub 2000/09/02. doi: 10.1016/S00063495(00)76372-7. PubMed PMID: 10968982; PMCID: PMC1301014.

68. Aliste MP, MacCallum JL, Tieleman DP. Molecular dynamics simulations of pentapeptides at interfaces: salt bridge and cation-pi interactions. Biochemistry. 2003;42(30):8976-87. Epub 2003/07/30. doi: 10.1021/bi027001j. PubMed PMID: 12885230. 
69. de Jesus AJ, Allen TW. The role of tryptophan side chains in membrane protein anchoring and hydrophobic mismatch. Biochim Biophys Acta. 2013;1828(2):864-76. Epub 2012/09/20. doi: 10.1016/j.bbamem.2012.09.009. PubMed PMID: 22989724.

70. de Planque MR, Kruijtzer JA, Liskamp RM, Marsh D, Greathouse DV, Koeppe RE, 2nd, de Kruijff B, Killian JA. Different membrane anchoring positions of tryptophan and lysine in synthetic transmembrane alpha-helical peptides. J Biol Chem. 1999;274(30):20839-46. Epub 1999/07/20. doi: 10.1074/jbc.274.30.20839. PubMed PMID: 10409625.

71. Petersen FN, Jensen $\mathrm{MO}$, Nielsen $\mathrm{CH}$. Interfacial tryptophan residues: a role for the cation-pi effect? Biophys J. 2005;89(6):3985-96. Epub 2005/09/10. doi:

10.1529/biophysj.105.061804. PubMed PMID: 16150973; PMCID: PMC1366964.

72. Yau WM, Wimley WC, Gawrisch K, White SH. The preference of tryptophan for membrane interfaces. Biochemistry. 1998;37(42):14713-8. Epub 1998/10/21. doi: 10.1021/bi980809c. PubMed PMID: 9778346.

73. Fox JM, Zhao M, Fink MJ, Kang K, Whitesides GM. The Molecular Origin of Enthalpy/Entropy Compensation in Biomolecular Recognition. Annu Rev Biophys. 2018;47:22350. Epub 2018/03/06. doi: 10.1146/annurev-biophys-070816-033743. PubMed PMID: 29505727.

74. Wang X, Yang X, Chen H, Yang X, Xu Z. Entropy-Enthalpy Compensation in Peptide Adsorption on Solid Surfaces: Dependence on Surface Hydration. Langmuir. 2020;36(36):10822-9. Epub 2020/08/20. doi: 10.1021/acs.langmuir.0c01845. PubMed PMID: 32813538.

75. Meier M, Seelig J. Length dependence of the coil <--> beta-sheet transition in a membrane environment. J Am Chem Soc. 2008;130(3):1017-24. Epub 2008/01/01. doi: 10.1021/ja077231r. PubMed PMID: 18163629.

76. Graber ZT, Thomas J, Johnson E, Gericke A, Kooijman EE. Effect of H-Bond Donor Lipids on Phosphatidylinositol-3,4,5-Trisphosphate Ionization and Clustering. Biophys J. 2018;114(1):126-36. Epub 2018/01/11. doi: 10.1016/j.bpj.2017.10.029. PubMed PMID: 29320679; PMCID: PMC5984899.

77. Kooijman EE, King KE, Gangoda M, Gericke A. Ionization properties of phosphatidylinositol polyphosphates in mixed model membranes. Biochemistry. 2009;48(40):9360-71. Epub 2009/09/04. doi: 10.1021/bi9008616. PubMed PMID: 19725516. 78. Scherer PG, Seelig J. Electric charge effects on phospholipid headgroups. Phosphatidylcholine in mixtures with cationic and anionic amphiphiles. Biochemistry. 1989;28(19):7720-8. Epub 1989/09/19. doi: 10.1021/bi00445a030. PubMed PMID: 2611211. 79. Andrushchenko VV, Aarabi MH, Nguyen LT, Prenner EJ, Vogel HJ. Thermodynamics of the interactions of tryptophan-rich cathelicidin antimicrobial peptides with model and natural membranes. Biochim Biophys Acta. 2008;1778(4):1004-14. Epub 2008/01/29. doi: 10.1016/j.bbamem.2007.12.022. PubMed PMID: 18222168.

80. Alder NN, Sutherland J, Buhring AI, Jensen RE, Johnson AE. Quaternary structure of the mitochondrial TIM23 complex reveals dynamic association between Tim23p and other subunits. Mol Biol Cell. 2008;19(1):159-70. Epub 2007/10/26. doi: 10.1091/mbc.e07-07-0669. PubMed PMID: 17959826; PMCID: PMC2174187.

81. Humphrey W, Dalke A, Schulten K. VMD: visual molecular dynamics. J Mol Graph. 1996;14(1):33-8, 27-8. Epub 1996/02/01. doi: 10.1016/0263-7855(96)00018-5. PubMed PMID: 8744570 .

82. Vanommeslaeghe K, Raman EP, MacKerell AD, Jr. Automation of the CHARMM General Force Field (CGenFF) II: assignment of bonded parameters and partial atomic charges. J Chem Inf Model. 2012;52(12):3155-68. Epub 2012/11/14. doi: 10.1021/ci3003649. PubMed PMID: 23145473; PMCID: PMC3528813. 
83. Pettersen EF, Goddard TD, Huang CC, Couch GS, Greenblatt DM, Meng EC, Ferrin TE. UCSF Chimera--a visualization system for exploratory research and analysis. J Comput Chem. 2004;25(13):1605-12. Epub 2004/07/21. doi: 10.1002/jcc.20084. PubMed PMID: 15264254. 84. Brooks BR, Brooks CL, 3rd, Mackerell AD, Jr., Nilsson L, Petrella RJ, Roux B, Won Y, Archontis G, Bartels C, Boresch S, Caflisch A, Caves L, Cui Q, Dinner AR, Feig M, Fischer S, Gao J, Hodoscek M, Im W, Kuczera K, Lazaridis T, Ma J, Ovchinnikov V, Paci E, Pastor RW, Post CB, Pu JZ, Schaefer M, Tidor B, Venable RM, Woodcock HL, Wu X, Yang W, York DM, Karplus M. CHARMM: the biomolecular simulation program. J Comput Chem. 2009;30(10):1545-614. Epub 2009/05/16. doi: 10.1002/jcc.21287. PubMed PMID: 19444816; PMCID: PMC2810661.

85. Huang J, Rauscher S, Nawrocki G, Ran T, Feig M, de Groot BL, Grubmuller H, MacKerell AD, Jr. CHARMM36m: an improved force field for folded and intrinsically disordered proteins. Nat Methods. 2017;14(1):71-3. Epub 2016/11/08. doi: 10.1038/nmeth.4067. PubMed PMID: 27819658; PMCID: PMC5199616.

86. Jo S, Kim T, lyer VG, Im W. CHARMM-GUI: a web-based graphical user interface for CHARMM. J Comput Chem. 2008;29(11):1859-65. Epub 2008/03/21. doi: 10.1002/jcc.20945. PubMed PMID: 18351591.

87. Khan HM, MacKerell AD, Jr., Reuter N. Cation-pi Interactions between Methylated Ammonium Groups and Tryptophan in the CHARMM36 Additive Force Field. J Chem Theory Comput. 2019;15(1):7-12. Epub 2018/12/19. doi: 10.1021/acs.jctc.8b00839. PubMed PMID: 30562013; PMCID: PMC6467778.

88. Lee J, Cheng X, Swails JM, Yeom MS, Eastman PK, Lemkul JA, Wei S, Buckner J, Jeong JC, Qi Y, Jo S, Pande VS, Case DA, Brooks CL, 3rd, MacKerell AD, Jr., Klauda JB, Im W. CHARMM-GUI Input Generator for NAMD, GROMACS, AMBER, OpenMM, and CHARMM/OpenMM Simulations Using the CHARMM36 Additive Force Field. J Chem Theory Comput. 2016;12(1):405-13. Epub 2015/12/04. doi: 10.1021/acs.jctc.5b00935. PubMed PMID: 26631602; PMCID: PMC4712441.

89. Jo S, Lim JB, Klauda JB, Im W. CHARMM-GUI Membrane Builder for mixed bilayers and its application to yeast membranes. Biophys J. 2009;97(1):50-8. Epub 2009/07/08. doi: 10.1016/j.bpj.2009.04.013. PubMed PMID: 19580743; PMCID: PMC2711372.

90. Bussi G, Donadio D, Parrinello M. Canonical sampling through velocity rescaling. J Chem Phys. 2007;126(1):014101. Epub 2007/01/11. doi: 10.1063/1.2408420. PubMed PMID: 17212484.

91. McGibbon RT, Beauchamp KA, Harrigan MP, Klein C, Swails JM, Hernandez CX, Schwantes CR, Wang LP, Lane TJ, Pande VS. MDTraj: A Modern Open Library for the Analysis of Molecular Dynamics Trajectories. Biophys J. 2015;109(8):1528-32. Epub 2015/10/22. doi: 10.1016/j.bpj.2015.08.015. PubMed PMID: 26488642; PMCID: PMC4623899.

92. Harris CR, Millman KJ, van der Walt SJ, Gommers R, Virtanen P, Cournapeau D, Wieser E, Taylor J, Berg S, Smith NJ, Kern R, Picus M, Hoyer S, van Kerkwijk MH, Brett M, Haldane A, Del Rio JF, Wiebe M, Peterson P, Gerard-Marchant P, Sheppard K, Reddy T, Weckesser W, Abbasi H, Gohlke C, Oliphant TE. Array programming with NumPy. Nature. 2020;585(7825):357-62. Epub 2020/09/18. doi: 10.1038/s41586-020-2649-2. PubMed PMID: 32939066; PMCID: PMC7759461.

93. Walt Svd, Colbert SC, Varoquaux G. The NumPy array: a structure for efficieint numerical computaiton. Computing in Science \& Engineering. 2011;13:22-30.

94. Virtanen P, Gommers R, Oliphant TE, Haberland M, Reddy T, Cournapeau D, Burovski E, Peterson P, Weckesser W, Bright J, van der Walt SJ, Brett M, Wilson J, Millman KJ, Mayorov N, Nelson ARJ, Jones E, Kern R, Larson E, Carey CJ, Polat I, Feng Y, Moore EW, VanderPlas J, Laxalde D, Perktold J, Cimrman R, Henriksen I, Quintero EA, Harris CR, Archibald AM, Ribeiro AH, Pedregosa F, van Mulbregt P, SciPy C. SciPy 1.0: fundamental algorithms for 
scientific computing in Python. Nat Methods. 2020;17(3):261-72. Epub 2020/02/06. doi: 10.1038/s41592-019-0686-2. PubMed PMID: 32015543; PMCID: PMC7056644.

95. Reback J, jbrockmendel, McKinney W, Bossche JVd, Augspurger T, Cloud P, Hawkins S, gfyoung, Roeschke M, Sinhrks, Klein A, Petersen T, Tratner J, She C, Ayd W, Hoefler P, Naveh S, Garcia M, Schendel J, Hayden A, Saxton D, Darbyshire J, Shadrach R, Gorelli ME, Li F, Zeitlin M, Jancauskas V, McMaster A, Battiston; P, Seabold S. pandas-dev/pandas: Pandas 1.3.4 https://zenodo.org/record/5574486\#.YW85jC-B1pQ2021.

96. Eisenhaber F, Lijnzaad P, Argos P, Sander C, Scharf M. The double cubic lattice method: Efficient approaches to numerical integration of surface area and volume and to dot surface contouring of molecular assemblies. J Comput Chem. 1995;16:273-84.

97. Grossfield A, Zuckerman DM. Quantifying uncertainty and sampling quality in biomolecular simulations. Annual Reports in Computational Chemistry. 2009;5:23-48. doi: doi:10.1016/S1574-1400(09)00502-7.

98. Caswell TA, Droettboom M, Lee A, Andrade ESd, Hoffmann T, Hunter J, Klymak J, Firing E, Stansby D, Varoquaux N, Nielsen JH, Root B, May R, Elson P, Seppänen JK, Dale D, Lee J-J, McDougall D, Straw A, Hobson P, hannah, Gohlke C, Vincent AF, Yu TS, Ma E, Silvester S, Moad C, Kniazev N, Ernest E, Ivanov P. Matplotlib/matplotlib: REL: V3.5.0rc1. 2021.

99. Wüthrich K. NMR of proteins and nucleic acids. New York: John Wiley \& Sons; 1986. 100. Jarori GK, Murali N, Rao BD. Two-dimensional transferred nuclear Overhauser effect spectroscopy study of the confirmation of MgATP bound at the active and ancillary sites of rabbit muscle pyruvate kinase. Biochemistry. 1994;33(22):6784-91. Epub 1994/06/07. doi: 10.1021/bi00188a006. PubMed PMID: 8204612.

101. Vranken WF, Boucher W, Stevens TJ, Fogh RH, Pajon A, Llinas M, Ulrich EL, Markley JL, lonides J, Laue ED. The CCPN data model for NMR spectroscopy: development of a software pipeline. Proteins. 2005;59(4):687-96. Epub 2005/04/09. doi: 10.1002/prot.20449. PubMed PMID: 15815974.

102. Schwieters CD, Kuszewski JJ, Tjandra N, Clore GM. The Xplor-NIH NMR molecular structure determination package. J Magn Reson. 2003;160(1):65-73. Epub 2003/02/05. doi: 10.1016/s1090-7807(02)00014-9. PubMed PMID: 12565051.

103. Maciejewski MW, Schuyler AD, Gryk MR, Moraru, II, Romero PR, Ulrich EL, Eghbalnia HR, Livny M, Delaglio F, Hoch JC. NMRbox: A Resource for Biomolecular NMR Computation. Biophys J. 2017;112(8):1529-34. Epub 2017/04/27. doi: 10.1016/j.bpj.2017.03.011. PubMed PMID: 28445744; PMCID: PMC5406371.

104. Jurrus E, Engel D, Star K, Monson K, Brandi J, Felberg LE, Brookes DH, Wilson L, Chen J, Liles K, Chun M, Li P, Gohara DW, Dolinsky T, Konecny R, Koes DR, Nielsen JE, HeadGordon T, Geng W, Krasny R, Wei GW, Holst MJ, McCammon JA, Baker NA. Improvements to the APBS biomolecular solvation software suite. Protein Sci. 2018;27(1):112-28. Epub 2017/08/25. doi: 10.1002/pro.3280. PubMed PMID: 28836357; PMCID: PMC5734301. 105. Koradi R, Billeter M, Wuthrich K. MOLMOL: a program for display and analysis of macromolecular structures. J Mol Graph. 1996;14(1):51-5, 29-32. Epub 1996/02/01. doi: 10.1016/0263-7855(96)00009-4. PubMed PMID: 8744573. 
A bioRxiv preprint doi: https://doi grg 101101/2021.11.08.467832; this yersion posted November 9, 2021. The copyright holder for this preprint

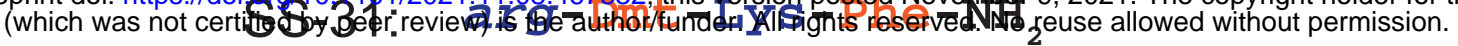

SS-20: $\quad$ Phe-arg-Phe-Lys- $\mathrm{NH}_{2}$

SPN4: arg-Tyr-Lys-Phe- $\mathrm{NH}_{2}$

SPN10: Trp-Arg-Trp-Lys-NH ${ }_{2}$

SS-31

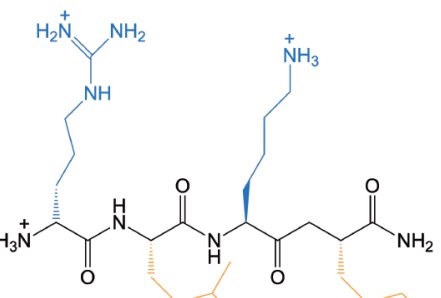

B

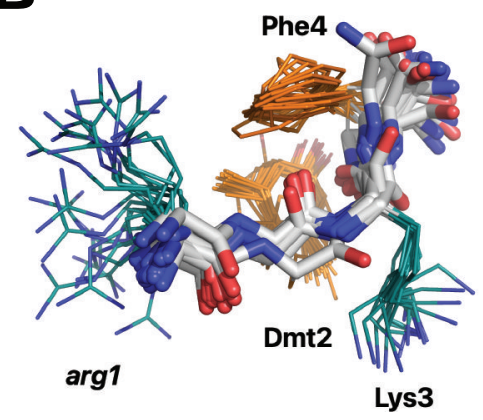

SS-20

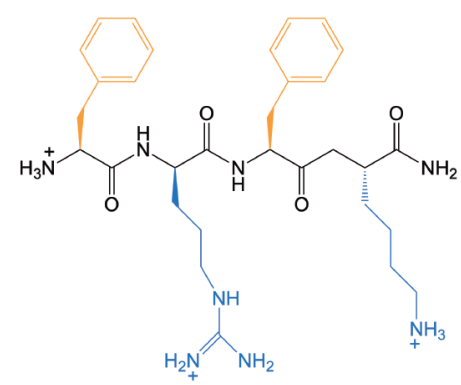

SPN4
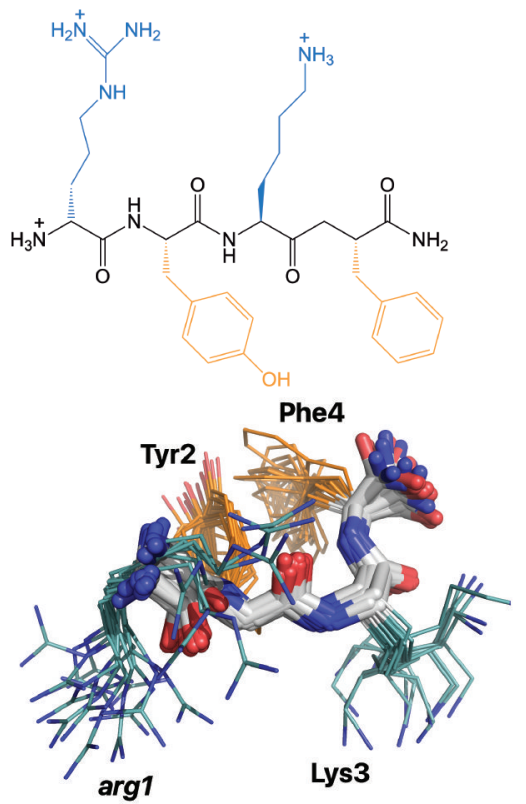

SPN10

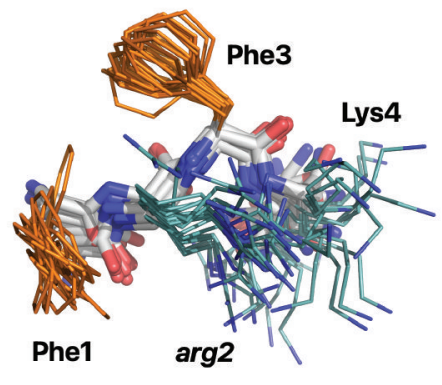

C

$\operatorname{NMR}\left[\begin{array}{ll}\boldsymbol{\square} & \text { solution } \\ \square & \text { membrane }\end{array}\right]$

SS-31

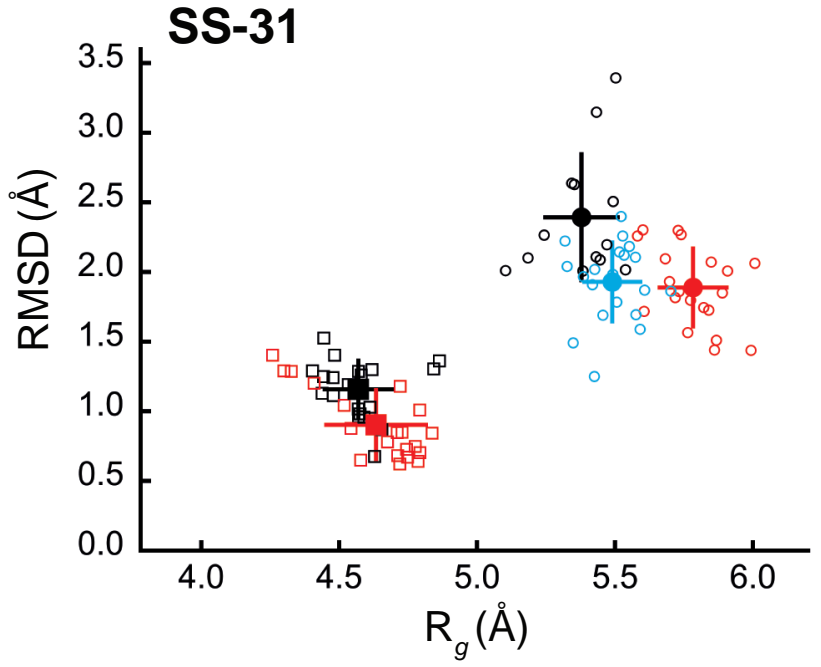

SPN4

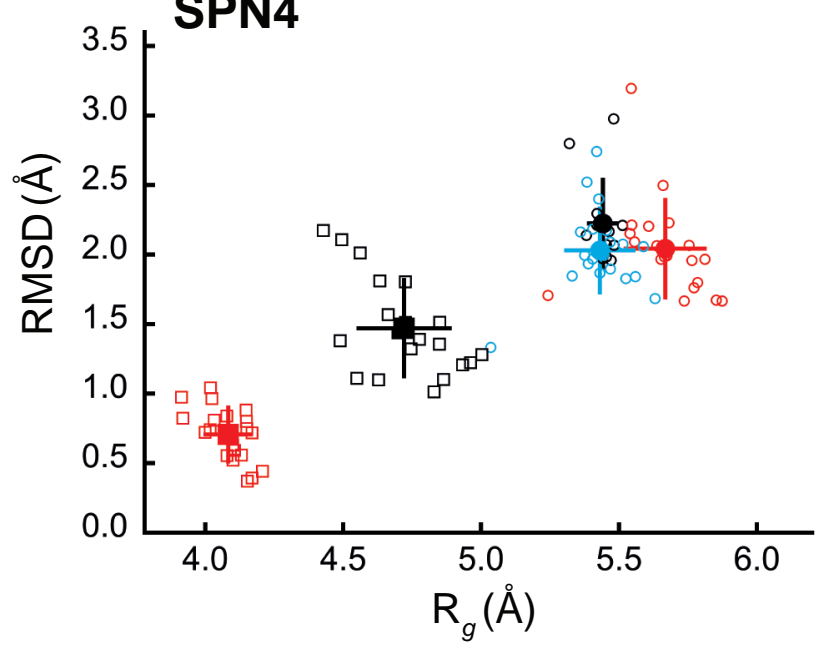

SS-20

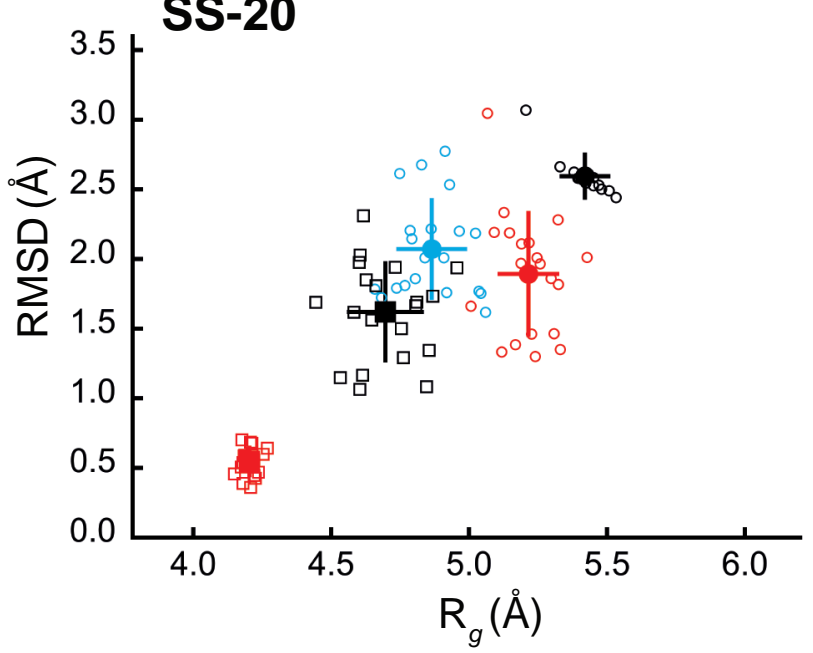

SPN10

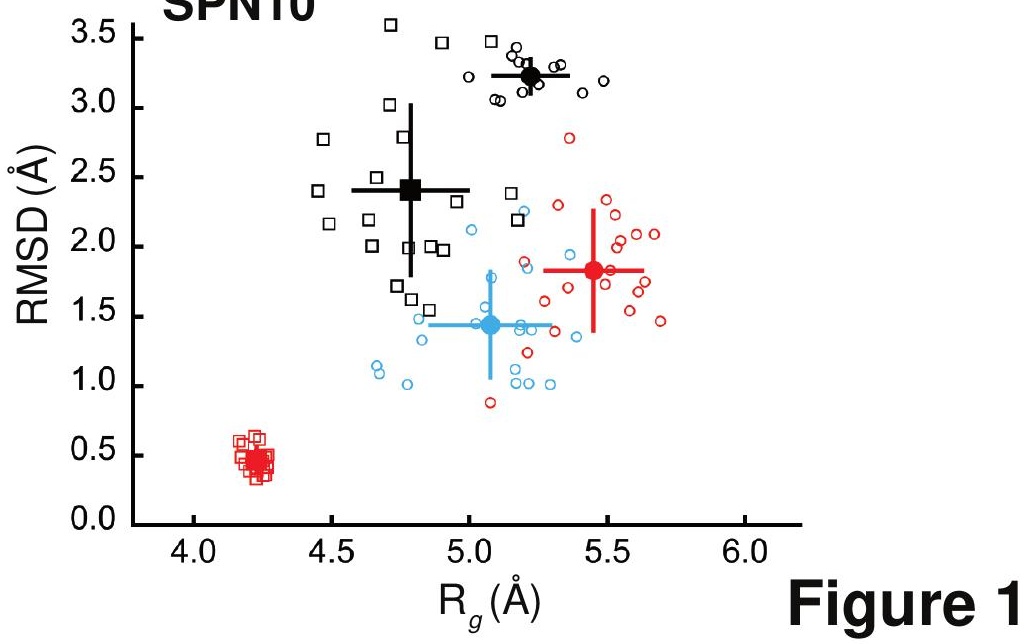


A

bioRxiv preprint doi: https://doi.org/10.1101/2021.11.08.467832; this version posted November 9, 2021. The copyright holder for this preprint (which was not certified by peer review) is the author/funder. All rights reserved. No reuse allowed without permission.

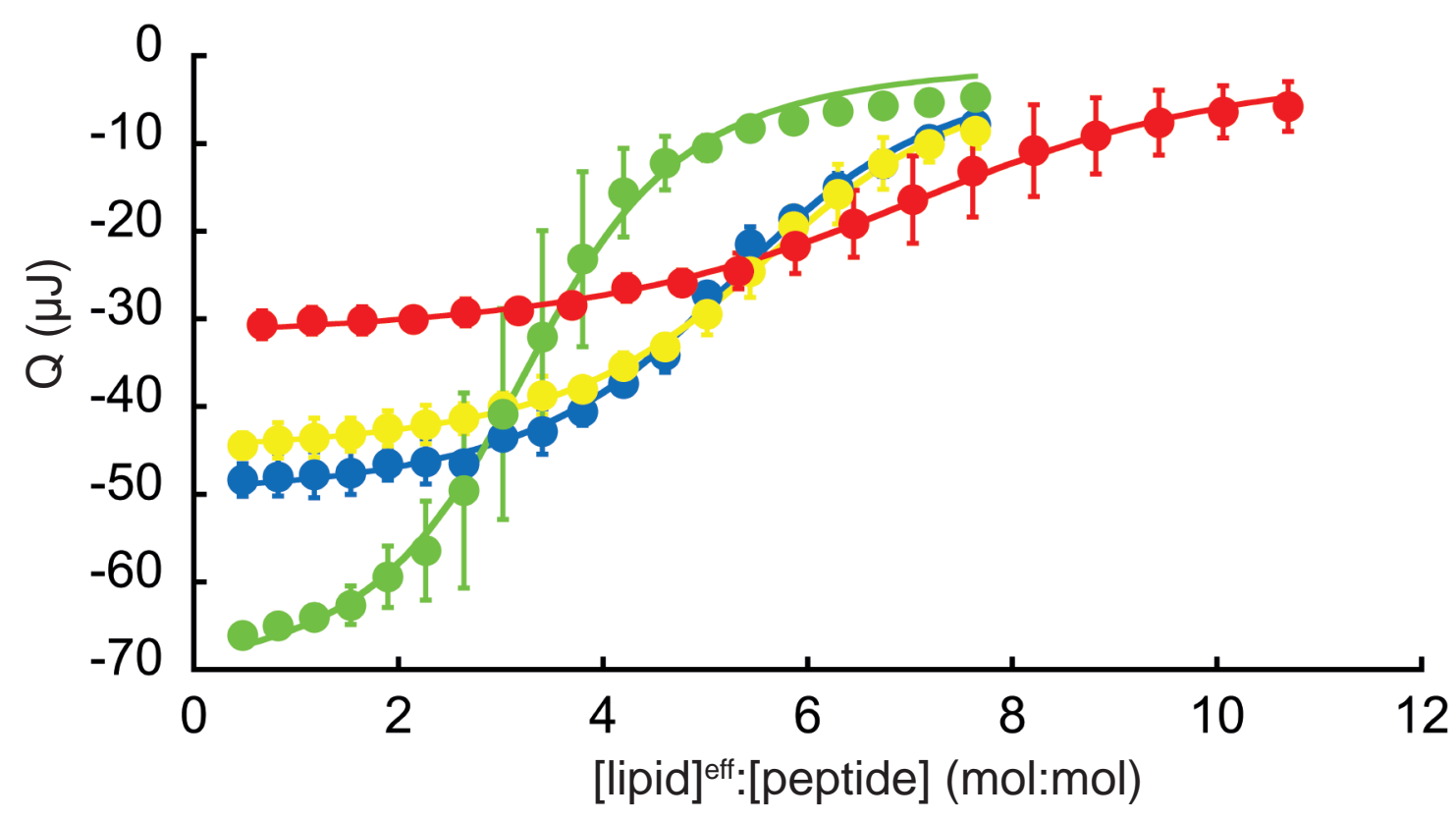

B
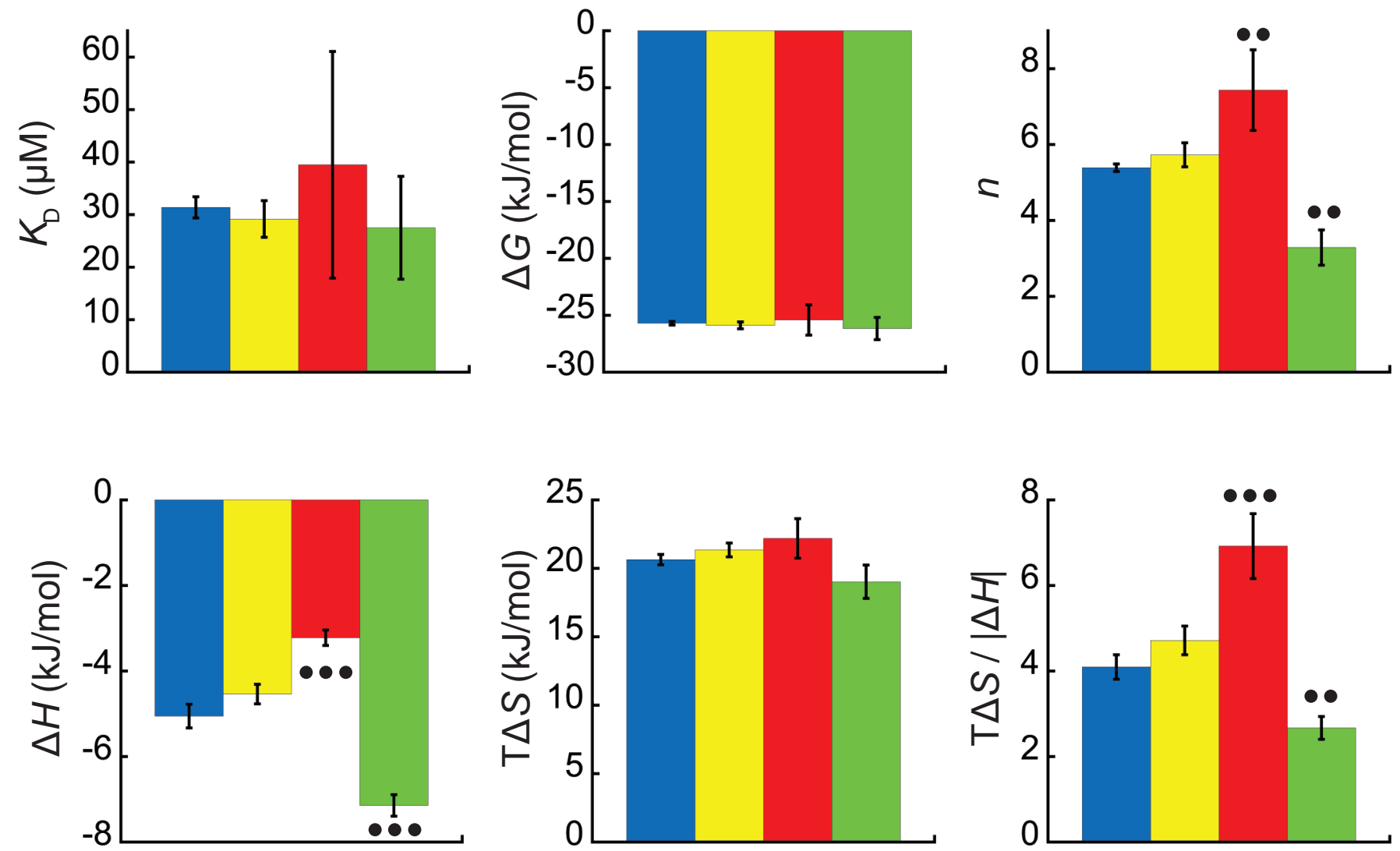
bioRxiv preprint doi: https://doi.org/10.1101/2021.11.08.467832; this version posted November 9, 2021. The copyright holder for this preprint (which was not certified by peer review) is the author/funder. All rights reserved. No reuse allowed without permission.

A

SPN10

SS-20

\section{SPN4}

SS-31
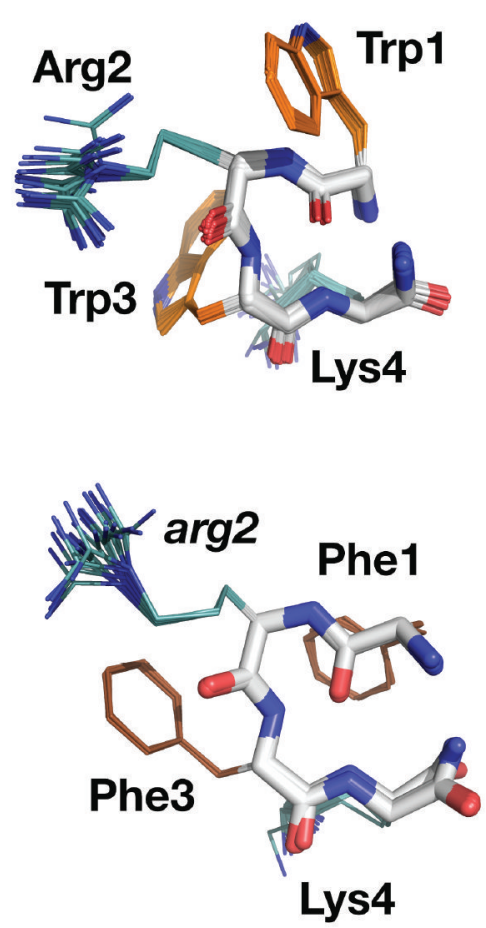

B
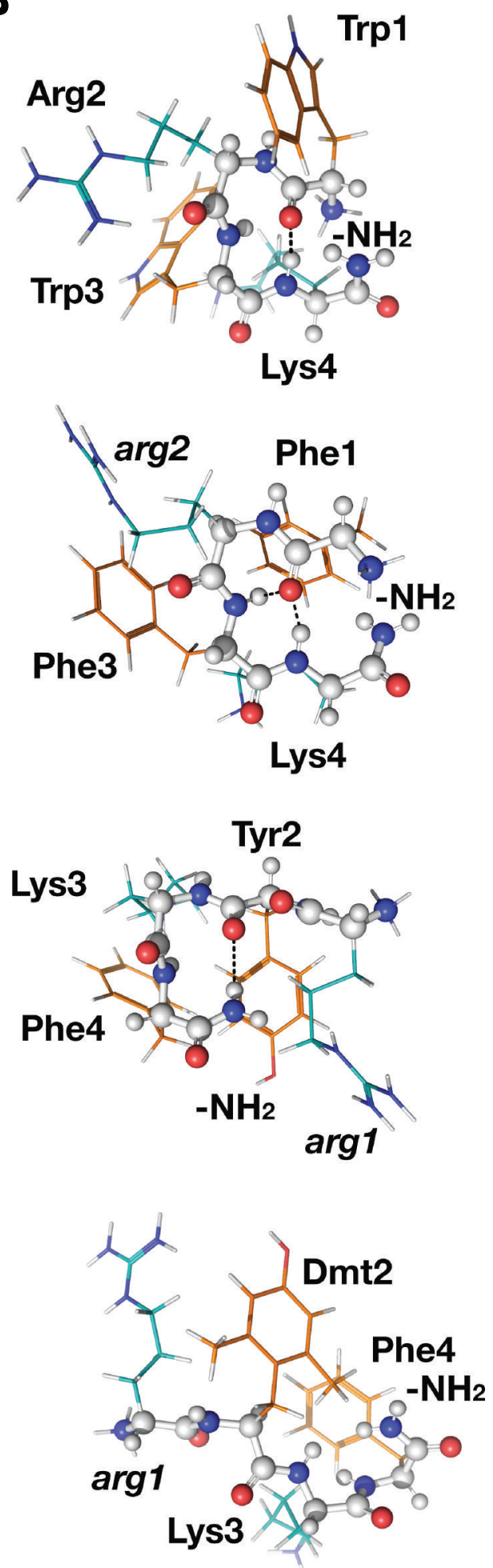


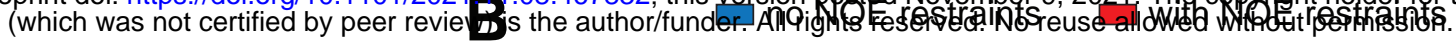
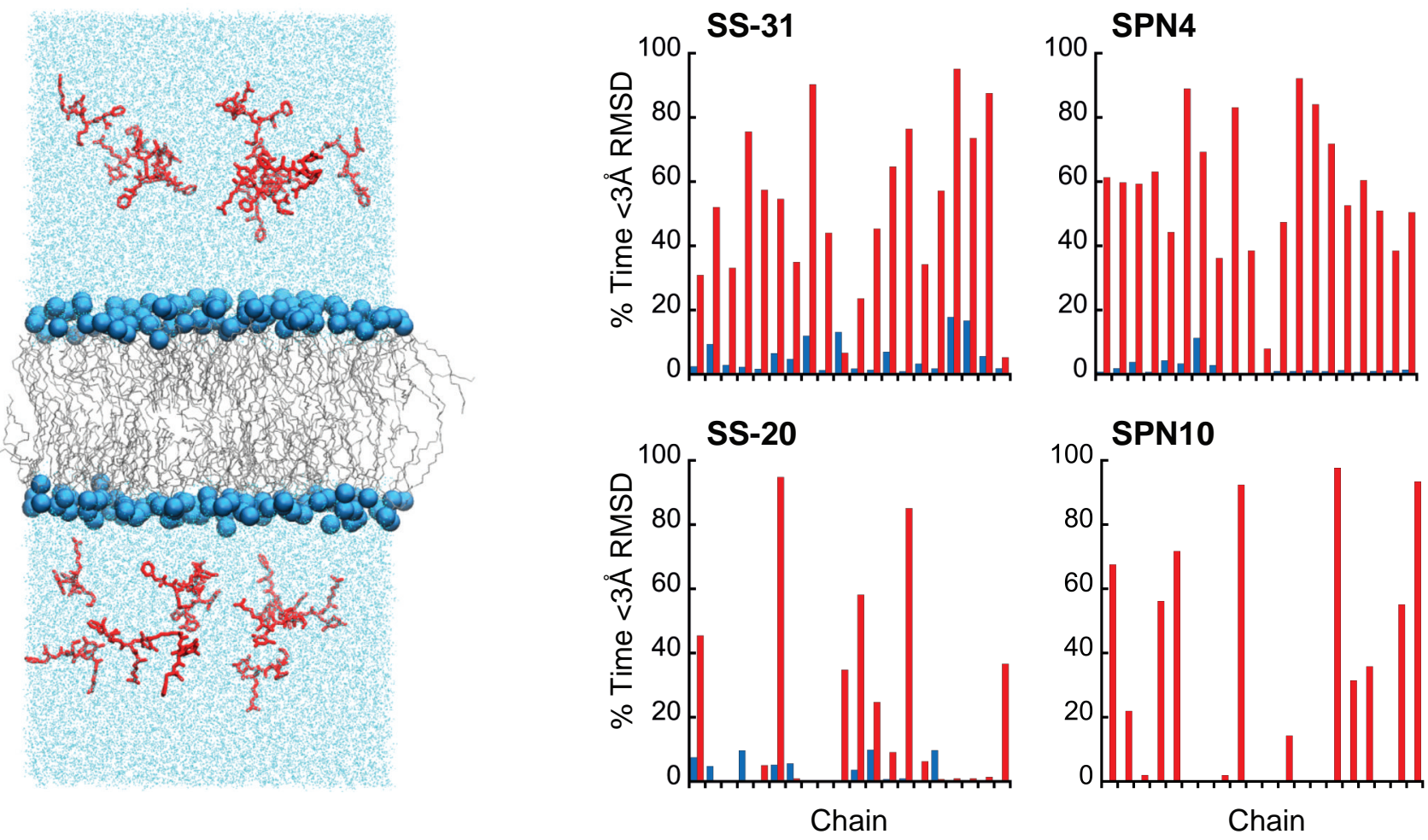

c

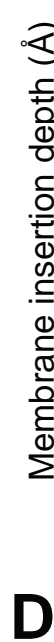

\section{SS-31}

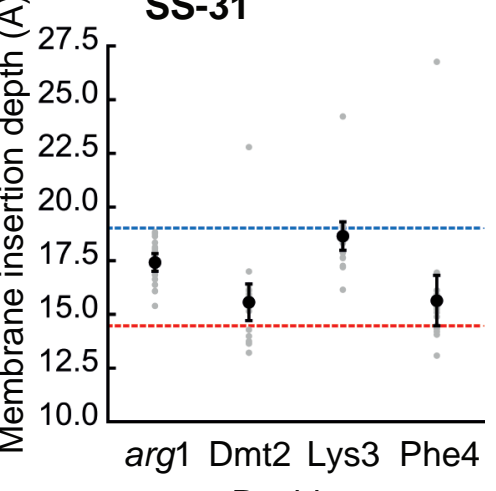

phosphate
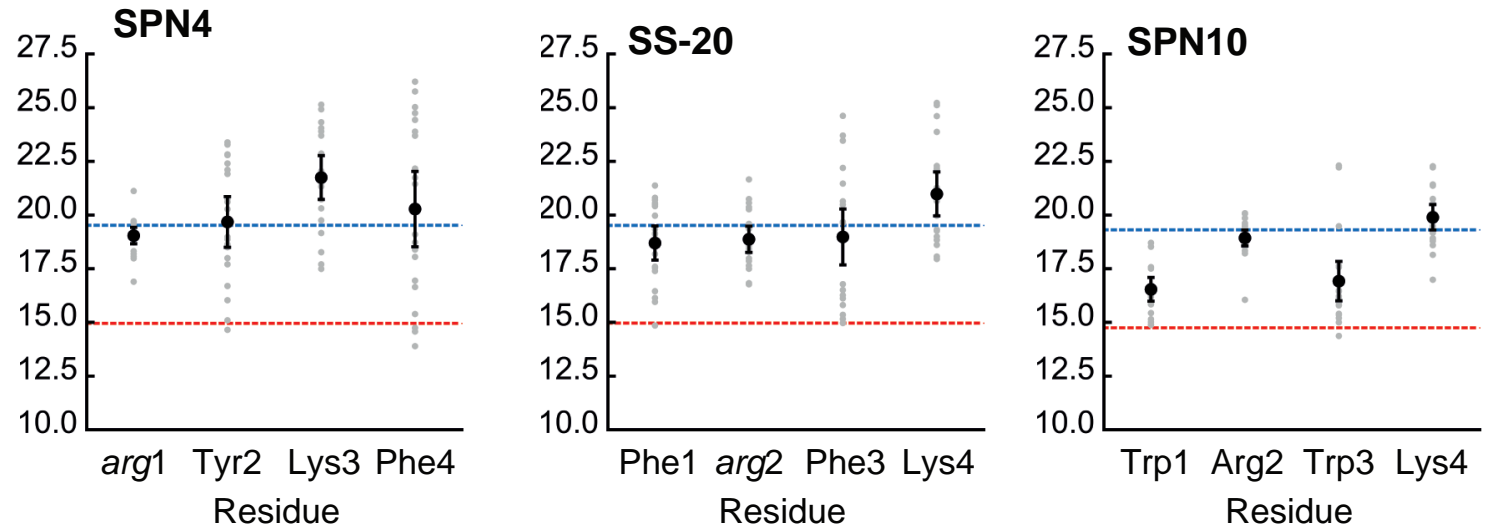

No peptide

SS-31

SPN4

SS-20

SPN10

relative to:
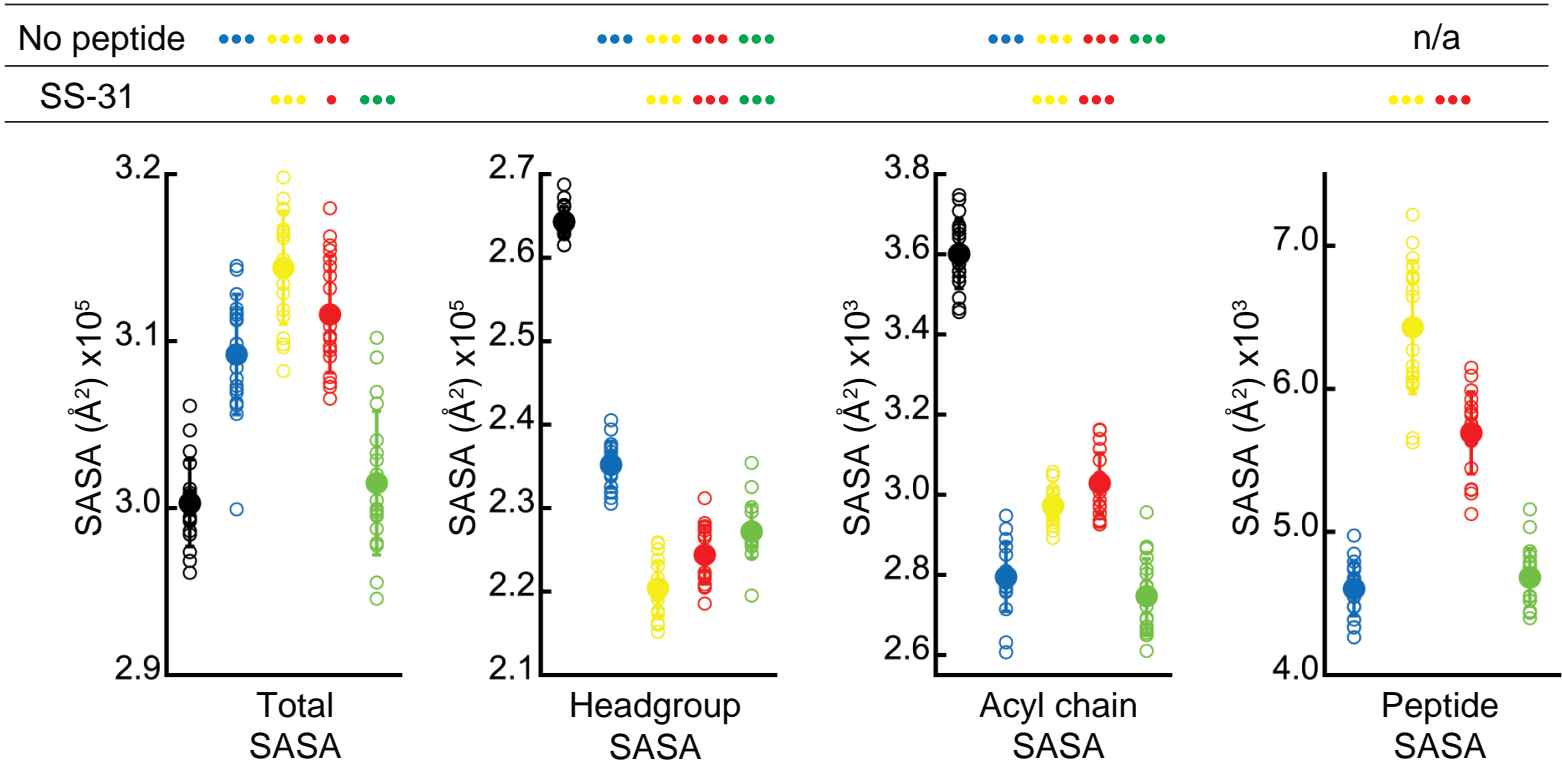

Figure 4 
A
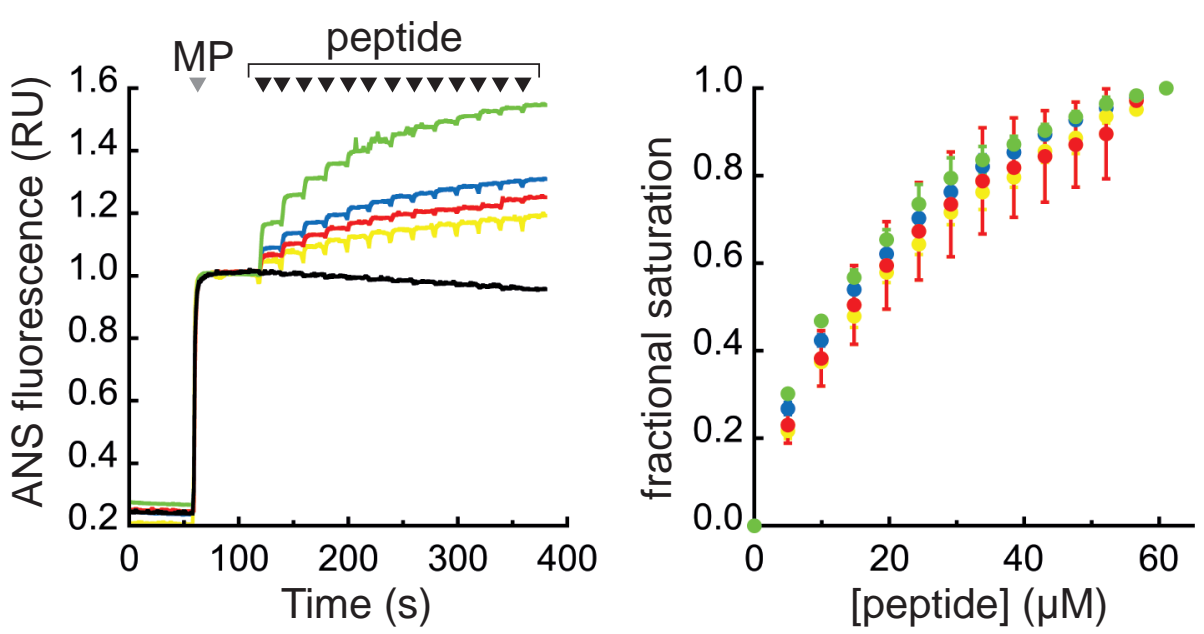

B
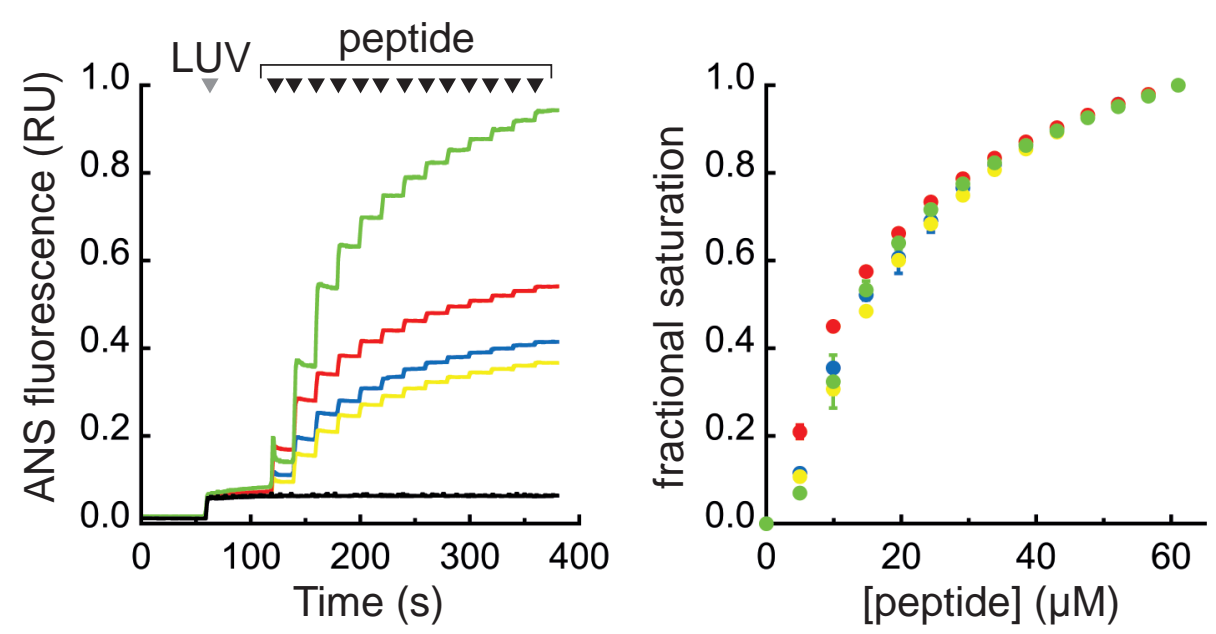

C
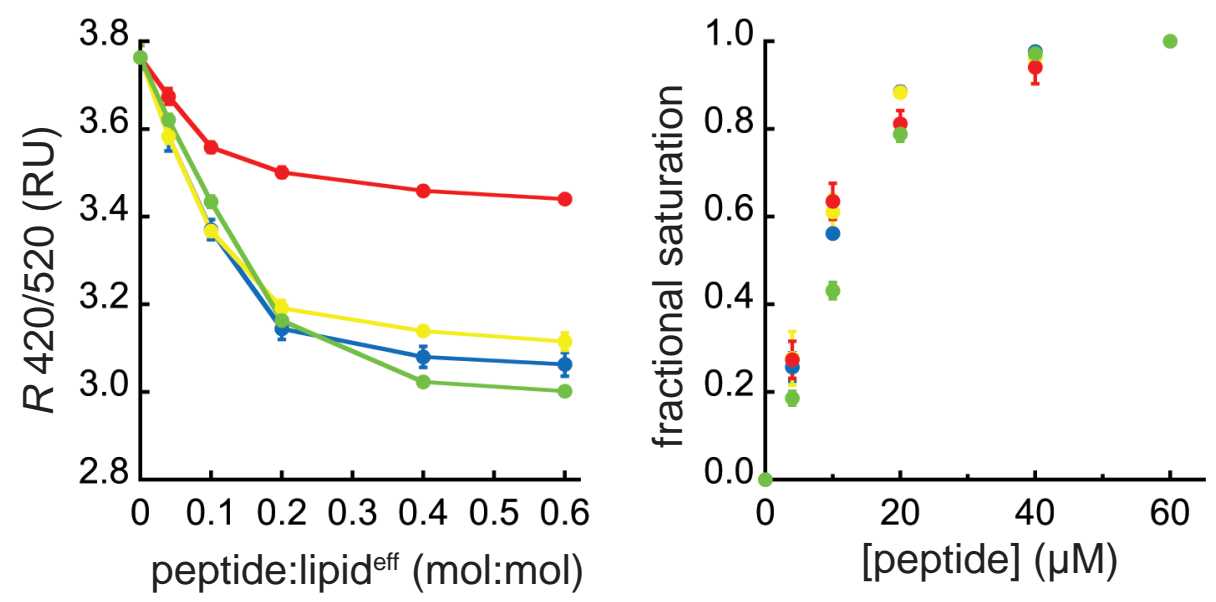

D
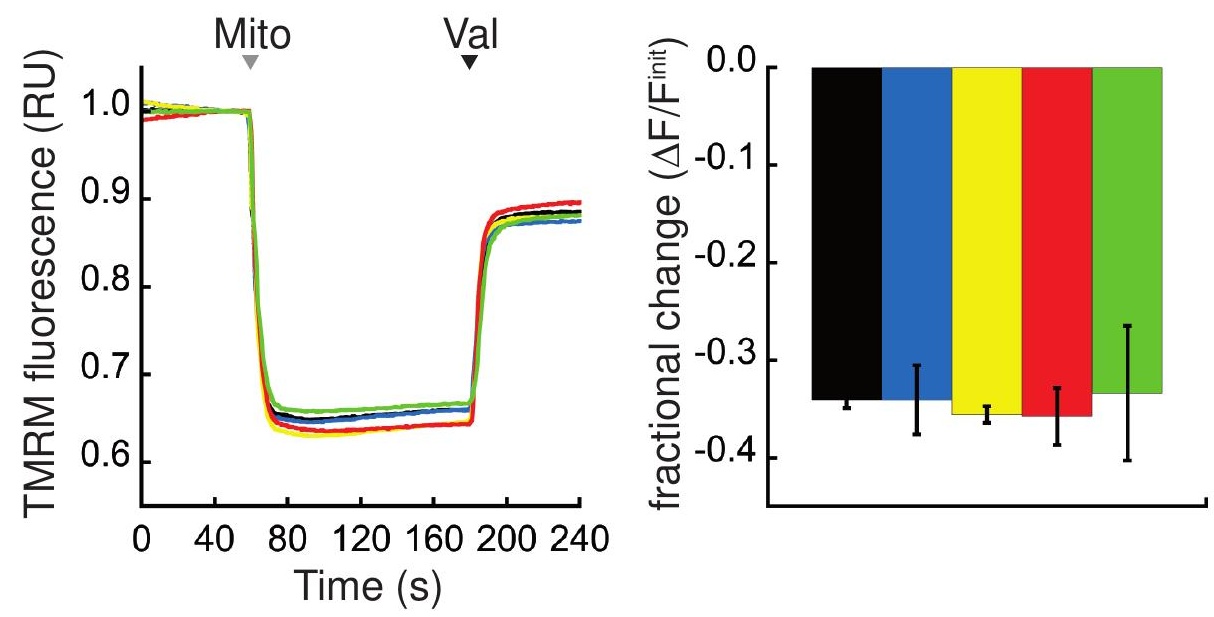
A

Background

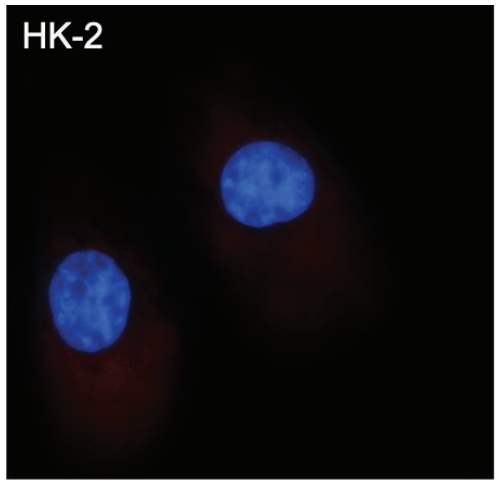

HK-2 cells

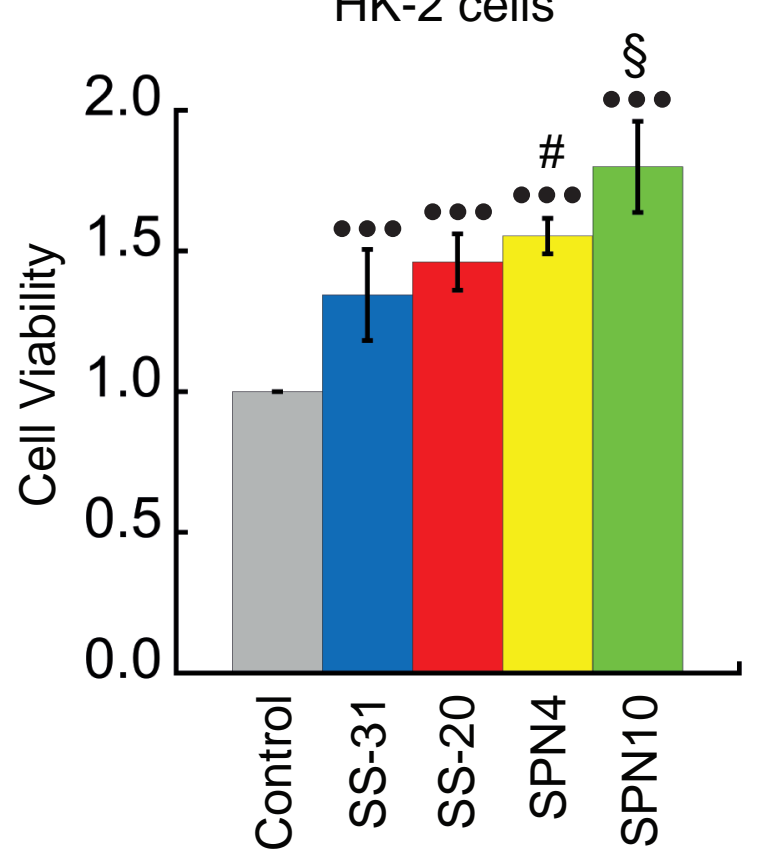

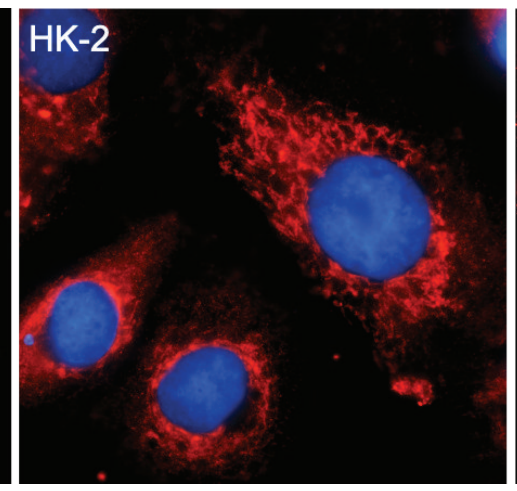

C

N-biotinylated SS-31

N-biotinylated SPN10
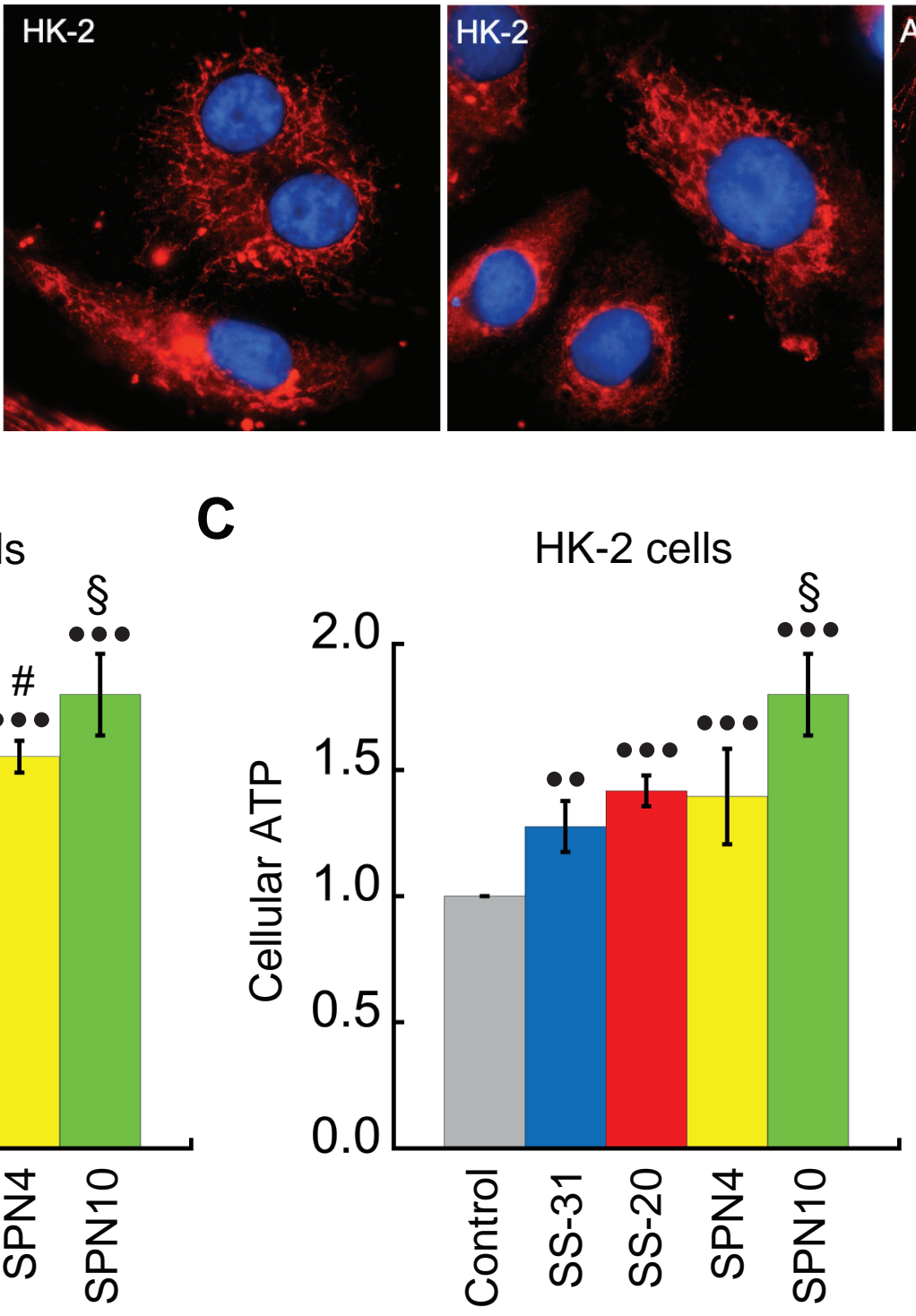

ARPE-19

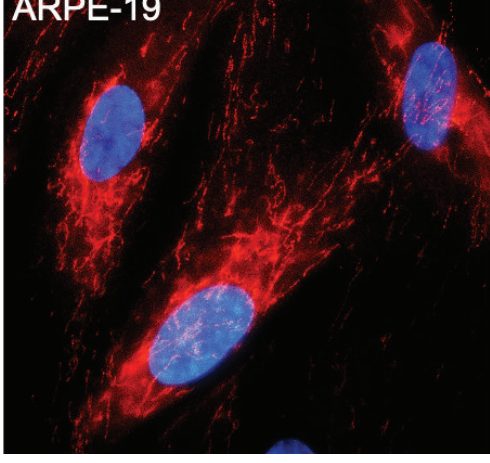

ARPE-19 cells

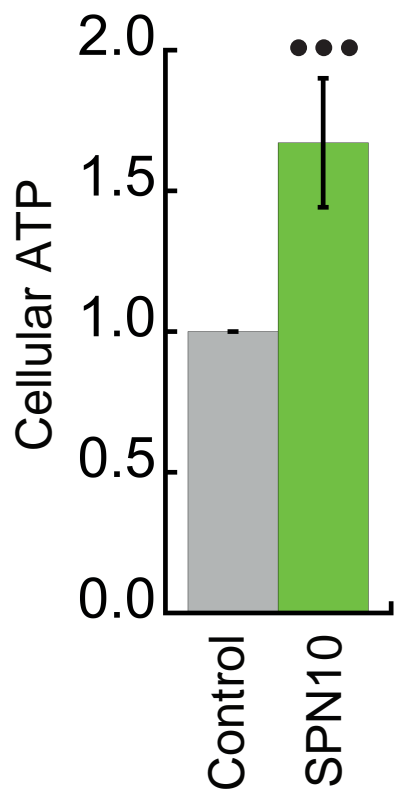

